\title{
The Earth's Magnetosphere: A Systems Science Overview and Assessment
}

\author{
Joseph E. Borovsky ${ }^{1}$ D . Juan Alejandro Valdivia ${ }^{2}$ (D)
}

Received: 3 April 2018 / Accepted: 7 July 2018 / Published online: 20 July 2018

(C) The Author(s) 2018

\begin{abstract}
A systems science examination of the Earth's fully interconnected dynamic magnetosphere is presented. Here the magnetospheric system (a.k.a. the magnetosphere-ionosphere-thermosphere system) is considered to be comprised of 14 interconnected subsystems, where each subsystem is a characteristic particle population: 12 of those particle populations are plasmas and two (the atmosphere and the hydrogen geocorona) are neutrals. For the magnetospheric system, an assessment is made of the applicability of several system descriptors, such as adaptive, nonlinear, dissipative, interdependent, open, irreversible, and complex. The 14 subsystems of the magnetospheric system are cataloged and described, and the various types of magnetospheric waves that couple the behaviors of the subsystems to each other are explained. This yields a roadmap of the connectivity of the magnetospheric system. Various forms of magnetospheric activity beyond geomagnetic activity are reviewed, and four examples of emergent phenomena in the Earth's magnetosphere are presented. Prior systems science investigations of the solar-wind-driven magnetospheric system are discussed: up to the present these investigations have not accounted for the full interconnectedness of the system. This overview and assessment of the Earth's magnetosphere hopes to facilitate (1) future global systems science studies that involve the entire interconnected magnetospheric system with its diverse time and spatial scales and (2) connections of magnetospheric systems science with the broader Earth systems science.
\end{abstract}

Keywords Magnetosphere $\cdot$ Complex systems $\cdot$ Systems science $\cdot$ Emergence $\cdot$ Coherent structure $\cdot$ Radiation belt

\section{Introduction}

The purposes of this review are (1) to provide an overview of the magnetospheric system (i.e., its subsystems and how the subsystems interact), to show how the system is driven by the solar wind, and how it reacts to the driving; (2) to describe the various phenomena that collectively make up magnetospheric activity; (3) to assess the system

Joseph E. Borovsky

jborovsky@spacescience.org

1 Center for Space Plasma Physics, Space Science Institute, Boulder, CO 80301, USA

2 Departmento de Fisica, Facultad de Ciencias, Universidad de Chile, 7800003 Santiago, Chile 
properties of the magnetosphere; and (4) to briefly discuss systems science studies of the magnetosphere that have been performed and that have yet to be performed. The motivation for this overview is the statement of Lin et al. (2013). "Thus, when hoping to understand the behaviors of a complex system, one needs to analyze not only how different components work together to form the behaviors of the whole system, but also the behaviors of the individual parts. Without deep and specific comprehension of the behaviors of the individual parts, there will be no way to capture the behaviors of the complex system." Systems science studies of the magnetosphere have been ongoing for a few decades, mostly focused on the analysis of a single measure of magnetospheric activity. This review will encourage more such studies and will try to lay a foundation for future studies dealing with the global nature of the magnetospheric system and its interaction with the Earth system. At present, such global studies do not exist.

This paper is aimed primarily at four types of readers: (1) a systems scientist who wants to think about this complicated, rich, important system, (2) an Earth systems scientist who wants to know how the magnetospheric system operates and influences the atmosphere and atmospheric electricity, (3) a beginning magnetospheric researcher who could utilize an overview of how the magnetosphere operates, and (4) a magnetospheric expert interesting in applying systems science to the magnetosphere.

An understanding of the Earth's magnetosphere is important for a number of reasons. (1) It is the environment that the Earth exists in and so it is natural to want to understand that environment. (2) The Earth's magnetosphere is also the closest astrophysical system that can be studied, and it is a very-well-measured system. (3) The activation of the Earth's magnetosphere by the solar wind gives rise to "space weather," which poses real dangers to astronauts, to the operation of spacecraft, and to electrical power grids at high latitudes, among others: based on magnetospheric physics, there is a substantial research effort to understand and forecast space weather. (4) The precipitation of energetic electrons from the magnetosphere into the atmosphere affects the chemistry and degree of ionization of the middle atmosphere and ionospheric Joule heating from the magnetosphere affects thermospheric temperatures, densities, and winds, and therefore, the magnetosphere plays a role in Earth systems science. (5) The magnetosphere provides a unique laboratory for plasma physics, especially for the all-important process of magnetic-field-line reconnection and also for the physics of collisionless shocks.

This paper is organized as follows: In Sect. 2, an overview of the Earth's magnetospheric system as driven by the time-dependent solar wind is given. In Sect. 3, the morphology and geographic regions of the magnetosphere are discussed. In Sect. 4, some physical processes that are important for the operation of the magnetospheric system are explained. The diverse particle populations of the magnetosphere, considered here as the subsystems of the magnetospheric system, are cataloged and discussed in Sect. 5. In Sect. 6, the various types of waves in the magnetosphere are cataloged and discussed: plasma waves are the manner by which the various subsystems of the magnetosphere interact with each other. Section 7 discusses the various types of activity in the magnetospheric system, i.e., the many ways that the system responds to driving by the solar wind. Section 8 discusses emergent phenomena in the magnetospheric system when it is driven by the solar wind. Section 9 discusses a number of system descriptors (adjectives) and how they apply to the magnetospheric system, the most fundamental of which being the question of whether the Earth's magnetosphere is a "complex system." Section 10 briefly reviews systems science research that has been performed on the Earth's magnetosphere as driven by the solar wind and discusses how magnetospheric systems 
science fits into Earth systems science. Section 11 contains discussions about things that are not yet known about the operation of the Earth's magnetosphere.

\section{Overview of the Earth's Magnetosphere}

The interaction of the supersonic solar wind with the Earth's dipole magnetic field is surprisingly complicated. About 5 orders of magnitude of spatial scales are involved in the global behavior of the magnetospheric system and timescales from seconds for the auroral pulsations (Yamamoto 1988), to several minutes for the reaction of the global magnetosphere to solar-wind pressure changes (Boudouridis et al. 2011), to several days for the intensification of the electron radiation belt (Balikhin et al. 2011), to years for the decay of relativistic electrons (Stassinopoulos and Verzariu 1971). Plasma-physical length scales vary from a Debye length of $0.4 \mathrm{~cm}$ in the ionosphere to ion gyroradii of $1000 \mathrm{~km}$ in the magnetotail and in the ion radiation belt; plasma-physical timescales associated with wave substructure can also be very short.

The Earth's magnetosphere is the spatial domain of the magnetic-field lines that connect to the Earth. This is sketched in Fig. 1, with the magnetosphere shaded in pink. Note the spatial scale indicated at the bottom in units of Earth radii $R_{\mathrm{E}}$, with $1 R_{\mathrm{E}}=6378 \mathrm{~km}$. A magnetic field has the property that it holds charged particles (ions and electrons), and when ions and electrons build up in the magnetic field to a sufficient density, they become a gas (called a plasma) that exhibits electromagnetic collective behavior such as plasma waves. The plasma can be described as having a number density $n$ and a temperature $T$, and it can have a vector flow velocity $\underline{v}$. There are multiple plasma populations with diverse properties that build up and evolve in the Earth's magnetosphere (cf. Fig. 2). The different plasmas interact with each other via different types of electromagnetic plasma waves that grow and damp throughout the magnetosphere.

The evolution and activation of the Earth's magnetosphere is driven by the solar wind, which is a supersonic magnetized plasma wind from the Sun that fills the solar system (Richardson 2013). Typical speeds of the solar wind are 300-800 km/s. Without the solar wind, the Earth's magnetosphere would be a magnetic dipole. However, the magnetosphere is distorted by the solar wind (see Fig. 1): it is compressed on the sunward side (dayside) and pulled out into a long tail on the anti-sunward side

Fig. 1 A depiction of the Earth (blue) and its magnetosphere (shaded in pink) bathed in solarwind plasma (yellow). The thin black lines are magnetic-field lines. The solar-wind plasma is flowing from left to right

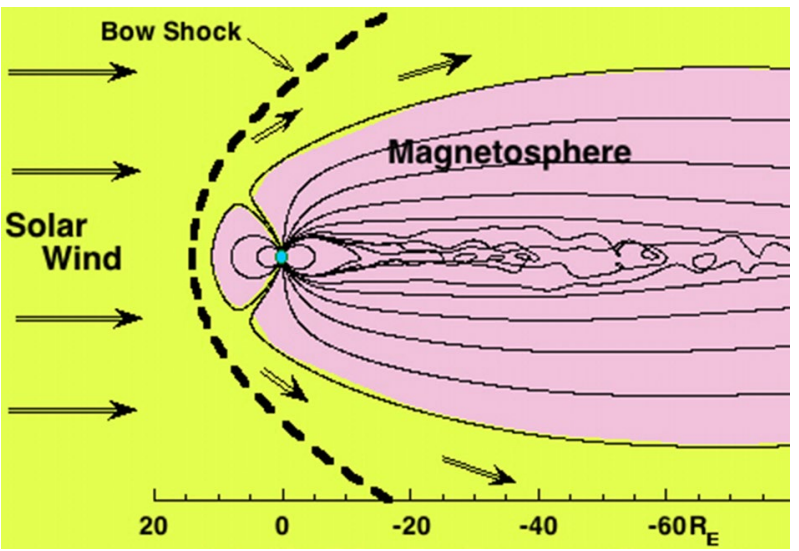


Fig. 2 The ranges of temperature (vertical) and number density (horizontal axis) of several of the plasmas of the Earth's magnetosphere are plotted. The values for the ion and electron radiation belt pertain to values seen at geosynchronous orbit: closer to the Earth those populations are hotter

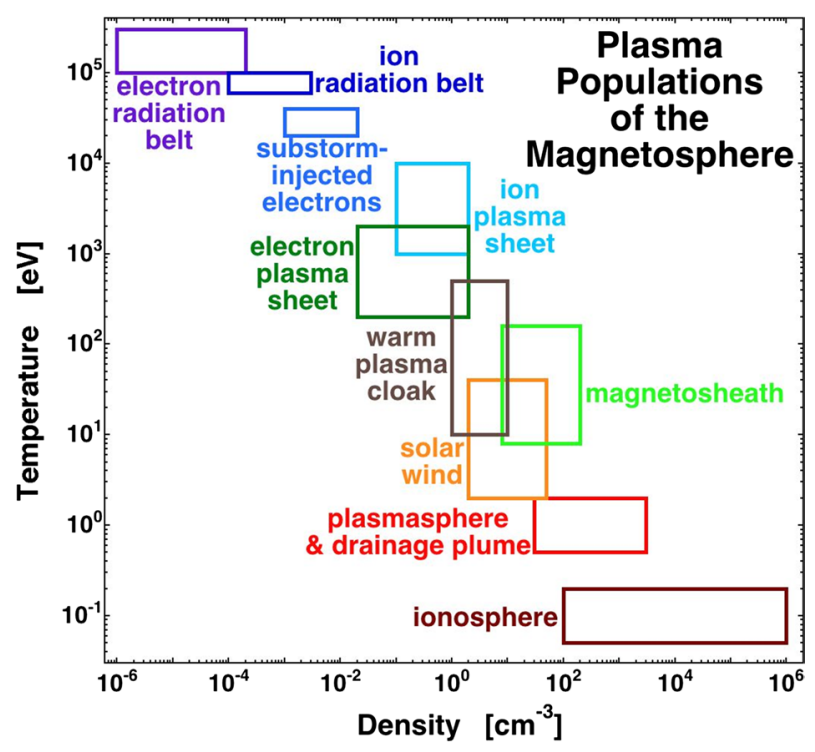

(nightside). The magnetosphere being driven by the solar wind means that the solar wind transfers plasma and energy into the magnetosphere, and very importantly, it sets up a global convection of plasma in the magnetosphere. This convection is important for transporting plasmas inside the magnetosphere, for energizing plasma, for driving waves in the plasmas, and for exhausting plasma out of the magnetosphere. At Earth, the properties of the solar wind vary with time owing (1) to the spotty sources of wind on the Sun's surface and the 27-day rotation of the Sun as seen by Earth and (2) to the fine-scale spatial structure of the solar-wind plasma; this means that the strength and details of the driving of the magnetosphere vary with time.

The Earth's magnetosphere has been measured by spacecraft instrumentation since the 1960s (Stern 1996). Much of the spacecraft data is publically available from the NASA Space Physics Data Facility at https://cdaweb.sci.gsfc.nasa.gov/index.html/, and solar-wind measurements at Earth from 1963 to the present are available at https ://omniweb.gsfc.nasa.gov. Sections 3-7 will explain several aspects of the magnetospheric system. There are also excellent tutorials about the Earth's magnetosphere (Lyon 2000; Otto 2005; Siscoe 2011; Eastwood et al. 2015) and excellent textbooks (Egeland et al. 1973; Jursa 1985; Hargreaves 1992; Kivelson and Russell 1995; Gombosi 1998).

The magnetosphere exhibits several classic systems aspects (cf. Sect. 10). (1) The magnetosphere is comprised of multiple interacting subsystems (the various plasmas). (2) The physical interactions within the system are multiscale, both local and global: small scale is $\sim 1 \mathrm{~km}$ (e.g., the reconnection diffusion region), global is $3 \times 10^{5} \mathrm{~km}$, with the global morphology of the magnetosphere at times being strongly affected by a single reconnection diffusion region set up either at the front of the magnetosphere or in the magnetotail. (3) The magnetosphere has a region that is turbulent and the magnetosphere exhibits some behavior that appears chaotic. (4) It will be shown in Sect. 8 that the magnetosphere exhibits emergent phenomena, so it could be argued that "the magnetosphere is greater than the sum of its parts." 


\section{The Morphology of the Magnetosphere}

The solar wind distorts the dipole magnetic field of the Earth, compressing the dayside and drawing the nightside out into a magnetotail. Note from Ampere's law of magnetism that every distortion of the magnetic field is associated with an electrical current. There are several current systems in the magnetosphere (Liemohn et al. 2015), but they will not be discussed here.

In Table 1, the names of several geographic regions of the Earth's magnetosphere are listed. The first location is the bow shock (Fairfield 1971; see Fig. 1). Because the solar wind is flowing supersonically at the Earth's magnetosphere, which is an obstacle to the flow, a shock wave forms in the flow converting the supersonic flow into a subsonic flow. The bow shock heats and compresses the solar-wind plasma and deflects the plasma flow around the magnetospheric obstacle.

The second region in Table 1 is the magnetopause (Safrankova et al. 2002). This is the outer boundary of the magnetosphere, the end of the domain wherein magnetic-field lines connect to the Earth. In Fig. 1, this is the boundary between the pink and yellow regions. Typically there are electrical currents flowing on the magnetopause. Just inside of the magnetopause there are "boundary layers": at low latitudes the boundary layer consists of a plasma called the low-latitude boundary layer (see Sect. 5) and at high latitudes the boundary layer consists of a plasma known as the mantle (see Sect. 5).

The third location in Table 1 is the dipolar region or inner magnetosphere (Olson and Pfitzer 1974) of the magnetosphere near the Earth. The strength of a dipole magnetic field falls off as $1 / r^{3}$, where $r$ is the radial distance, so that at small distances $r$ close to the Earth the magnetic field is strong and the distortions caused by the solar wind are not effective. The Earth rotates with a 24-h period, and the portion of the dipolar magnetosphere that is closest to the Earth corotates with the Earth, the cooler plasmas in that near-Earth region having a 24-h circulation period. (The corotation is caused by the tendency of the ionosphere to be collisionally coupled to the atmosphere (Rees 1989), which rotates with the

Table 1 Locations in the magnetospheric system

\begin{tabular}{ll}
\hline Location & Importance \\
\hline Bow shock & Processes cool solar wind into hot magnetosheath \\
Magnetopause & $\begin{array}{l}\text { Outer boundary of magnetosphere } \\
\text { Site of dayside reconnection }\end{array}$ \\
& A location of plasma entry into magnetosphere \\
& Traps plasma and energetic charged particles \\
Dipolar region & Reservoir of magnetic flux and energy \\
Magnetotail & Globally unstable at times: energy for substorms \\
& A source of plasma for magnetosphere \\
Ionosphere and thermosphere & An absorber of magnetospheric charged particles \\
Cusps & A location of plasma entry into magnetosphere \\
Auroral zone & A region of energy transfer from the magnetosphere to the ionosphere \\
Geosynchronous orbit & Populated with spacecraft, $r=6.6 R_{\mathrm{E}}$ \\
Lunar orbit & Orbit of the moon, $r=60 R_{\mathrm{E}}$ \\
L1 Lagrangian point & Location of upstream solar-wind monitors, $235 R_{\mathrm{E}}$ toward the Sun
\end{tabular}


Earth.) The radiation belts (see Sect. 5) reside in the dipolar region, as does the plasmasphere (see Sect. 5).

The fourth region in Table 1 is the magnetotail (Nishida 2000) on the nightside of the Earth. It is a very long (100's of $R_{\mathrm{E}}$ ), cylindrical volume of magnetic-field lines connected to the Earth, with solar-wind plasma flowing away from the Sun outside of the magnetotail. Within the magnetotail two important hot plasmas reside: the ion plasma sheet and the electron plasma sheet. The global pattern of convection in the magnetosphere is from nightside to dayside (opposite to the direction of the solar-wind flow), and the near-Earth portion of the magnetotail is a conduit for the delivery of hot plasma into the dipolar magnetosphere from the nightside. The magnetotail is a reservoir of magnetic energy that powers several magnetospheric processes. The magnetotail is subject to global instabilities that produce "substorms," which are surges of Earthward convection that occur on average a few times per day: accompanying the occurrence of a substorm, a magnetized plasmoid is ejected down the magnetotail to be lost from the Earth.

The ionosphere and the thermosphere. The thermosphere is the upper region (above $\sim 85 \mathrm{~km}$ ) of the neutral atmosphere. The ionosphere is the ionized portion of the thermosphere.

The cusps (Sandahl 2003) are features in the magnetic field of the magnetosphere close to the northern and southern poles of the Earth's dipole where solar-wind plasma can penetrate deep into the magnetosphere along the magnetic-field lines. In Fig. 1, the cusps can be seen as the two intrusions of yellow solar-wind plasma into the pink magnetosphere.

The auroral zone (Feldstein and Galperin 1985) is a ring around the northern polar region of the Earth and a ring around the southern polar region where magnetospheric electrons and ions impact the upper atmosphere to produce visible airglow. Most aurora are produced by electron impact from the electron plasma sheet. A weaker airglow is produced by proton impact (from the ion plasma sheet) on the atmosphere at latitudes slightly lower than the electron aurora. Aurora represent a large amount of power from the magnetosphere that is dissipated in the atmosphere and ionosphere.

Table 1 points out three other locations important to the magnetosphere. Geosynchronous orbit $\left(r=6.6 R_{\mathrm{E}}\right)$ is the location where a satellite has a gravitational orbit that has a 24-h period and hence where orbiting objects corotate with the surface of the Earth; geosynchronous orbit is heavily populated with communications satellites. Lunar orbit $(r \approx 60$ $R_{\mathrm{E}}$ ) is the location of the Moon's orbit, with the Moon crossing through the Earth's magnetotail when the Moon is full (cf. Fig. 1). The first Lagrangian point $L 1$ is $235 R_{\mathrm{E}}$ upstream of the Earth along the Sun-Earth line: it is a quasi-stable gravitational-orbit location that is used to place solar-wind-monitoring spacecraft upstream of the Earth. The solar-wind plasma that passes a spacecraft at L1 hits the Earth 30-60 min later (Weimer et al. 2003).

\section{Important Physical Processes}

There are several physical processes that are important to the operation of the Earth's magnetosphere.

Magnetic-field-line reconnection (Birn and Priest 2009) is an extremely important process for the magnetosphere. Reconnection changes the magnetic connection between two magnetized plasmas. There are two major sites of reconnection. (1) On the dayside magnetopause reconnection magnetically connects the moving solar-wind plasma to the magnetosphere. This magnetic connection allows the solar wind to couple to the magnetosphere, transferring 
plasma, magnetic field, momentum, and energy into the magnetosphere. The amount of reconnection (the reconnection rate) governs the amount of solar-wind/magnetosphere coupling; hence, it governs most of the driving of the magnetosphere by the solar wind. (2) In the magnetotail, reconnection changes the magnetic morphology of the tail, driving magnetospheric global convection and allowing the tail to move to a lower energy state, converting magnetic energy into flows, heating, and particle energization.

Several concepts relate to the orbits of charged particles in a magnetic field (Falthammar 1973). In a vacuum, charged particles move around a magnetic-field line in a spiral orbit, being free to move along the field line but performing circular (cyclotron) motion perpendicular to the field line. In a dipole magnetic field, charged particles perform bounce motion as they spiral, where there is a "mirror" force along the field line that pushes the particle toward the equator of the dipole, acting to keep it away from the Earth. For charged particles that have velocity vectors nearly parallel to the field line, this mirror force is ineffective and the charged particle can reach the Earth's atmosphere, where it is lost from the magnetosphere. Furthermore, energetic particles are subject to magnetic drifts, wherein the morphology of the magnetic field allows the particles to drift across the magnetic-field-line direction.

Cold plasma is transported in the magnetosphere differently from hot plasma. Cold plasma follows the convection of magnetic-field lines. The global magnetospheric convection of magnetic-field lines (Dungey 1961) is from the magnetotail sunward through the dipolar portion of the magnetosphere to the dayside magnetopause; hence, cooler plasmas follow this magnetic convection and they exit the magnetosphere at the dayside magnetopause. Note, however, very close to the earth there is a zone where the cold plasma corotates with the earth and is trapped. The convection of hot plasma tends to be dominated by the shape of the magnetic-field lines. The ions and electrons of the hottest plasmas tend to make circular orbits around the Earth, with the positive ions moving westward around the Earth and the negative electrons moving eastward around the Earth.

Plasma waves are electromagnetic fluctuations in the plasma. In a magnetized plasma, there is a "zoo" of different possible wave types (Walker 1993). If there is a free energy source (which there often is in the magnetosphere), the waves in the plasma can grow in amplitude (Gary 1993). For example, particular consideration can be given to the thermal and nonthermal properties of the particle velocity distribution functions which can have profound effects in wave propagation and generation, as well as thermal anisotropy that can provide a natural surge of free energy for the growth (Valdivia et al. 2016).

Wave-particle interactions (Tsurutani and Lakhina 1997) occur because the charged particles of a plasma react to the electric and magnetic fields of electromagnetic plasma waves. Two important consequences of wave-particle interactions are (a) particle energization, which heats the ions and/or electrons of a plasma and which can sometimes produce a new population of energetic particles, and (b) pitch-angle scattering, which changes the direction of a particles velocity vector with respect to the magnetic-field-line direction. Pitch-angle scattering allows some particles to overcome the mirror force such that the particles are "scattered" into the atmosphere and lost from the magnetosphere.

Finally, the ionospheric outflow of ions (Welling et al. 2015) is very important. The ionosphere (the ionized upper atmosphere) is a huge reservoir of cold ions that are gravitationally bound to the Earth. Various mechanisms can act to push ions upward out of the ionosphere along the magnetic-field lines into the magnetosphere. 


\section{The Particle Populations of the Magnetosphere: The Subsystems}

In one view of the magnetosphere as a system driven by the solar wind, the different particle populations of the magnetosphere can be considered as the interacting subsystems that make up the system. Of the 14 subsystems discussed in this section and listed in Table 2, the first 12 are ionized-particle populations and the last 2 are neutral-particle populations.

There are two sources for the plasmas in the magnetosphere: (1) solar-wind plasma entering into the magnetosphere across the magnetopause and/or into the cusps and (2) outflow from the ionosphere into the magnetosphere. Solar-wind-origin plasma has an ionic composition like that of the solar wind, comprised of $\mathrm{H}^{+}$and $\mathrm{He}^{++}$, while the ionospheric-origin plasma has an ionic composition of $\mathrm{H}^{+}, \mathrm{He}^{+}$, and $\mathrm{O}^{+}$. All of the plasmas have electrons. Excepting in very rare cases, plasmas are "charge neutral," having equal amounts of positive and negative charges in a certain volume.

Note that the different plasmas of the magnetosphere can be geographically overlapping (colocated). Colocated plasmas have the opportunity to strongly interact with each other via plasma waves.

In Table 2, the major plasmas of the magnetosphere are outlined. In Fig. 2, the number density $n$ and the temperature $T$ of most of those plasmas are indicated schematically, each plasma exhibiting a range of $n$ values and a range of $T$ values. Note that these number densities are extremely low by terrestrial standards: the number density of molecules in the atmosphere at sea level is $2.5 \times 10^{19} \mathrm{~cm}^{-3}$ and a very good vacuum in the laboratory is $3 \times 10^{9} \mathrm{~cm}^{-3}$. When we speak here of high density and low density, it is relative to magnetospheric values. The temperatures $\mathrm{T}$ are measured in units of electron Volts (eV), with $1 \mathrm{eV}=11,600 \mathrm{~K}$.

The first two plasmas discussed are boundaries of the magnetosphere that serve as plasma sources.

The ionosphere (Kelley 1989) is the ionized upper atmosphere beginning at a height of about $100 \mathrm{~km}$ above the ground. Most of the ionization comes from ultraviolet light from the Sun, but some of the ionization comes from the impact of energetic magnetospheric electrons onto the upper atmosphere. The ionosphere is more dense on the sunlit dayside of the Earth than it is on the nightside. The ionosphere is a major source of plasma for the magnetosphere, with magnetospheric activity affecting the rate of ion outflow. The outflow of cold electrons from the ionosphere (and of warmer photoelectrons from the atmosphere) is also important, allowing charge neutrality in the magnetosphere to be enforced. The ionosphere has its own set of rich phenomena that occur (e.g., instabilities, structuring, waves, flows; Hargreaves 1992; Blagoveshchenskii 2013): those ionospheric phenomena will not be considered here.

The magnetosheath (Kaymaz 1998) is the shocked solar-wind plasma that lies between the bow shock and the Earth's magnetopause. As the solar-wind plasma is shocked in passing through the bow shock, the cool solar-wind plasma is converted into a hot and more-dense magnetosheath plasma that flows around the magnetosphere. The magnetosheath is the solar-wind plasma that makes contact with and leaks into the magnetosphere.

The plasmasphere (Darrouzet et al. 2009) is a cold dense plasma in the dipolar region of the magnetosphere. The plasmasphere is of ionospheric origin, caused by sunlit-driven outflow of cold ions from the dayside ionosphere. Near the Earth the plasmasphere corotates with the Earth. The properties of the dense plasmasphere largely 


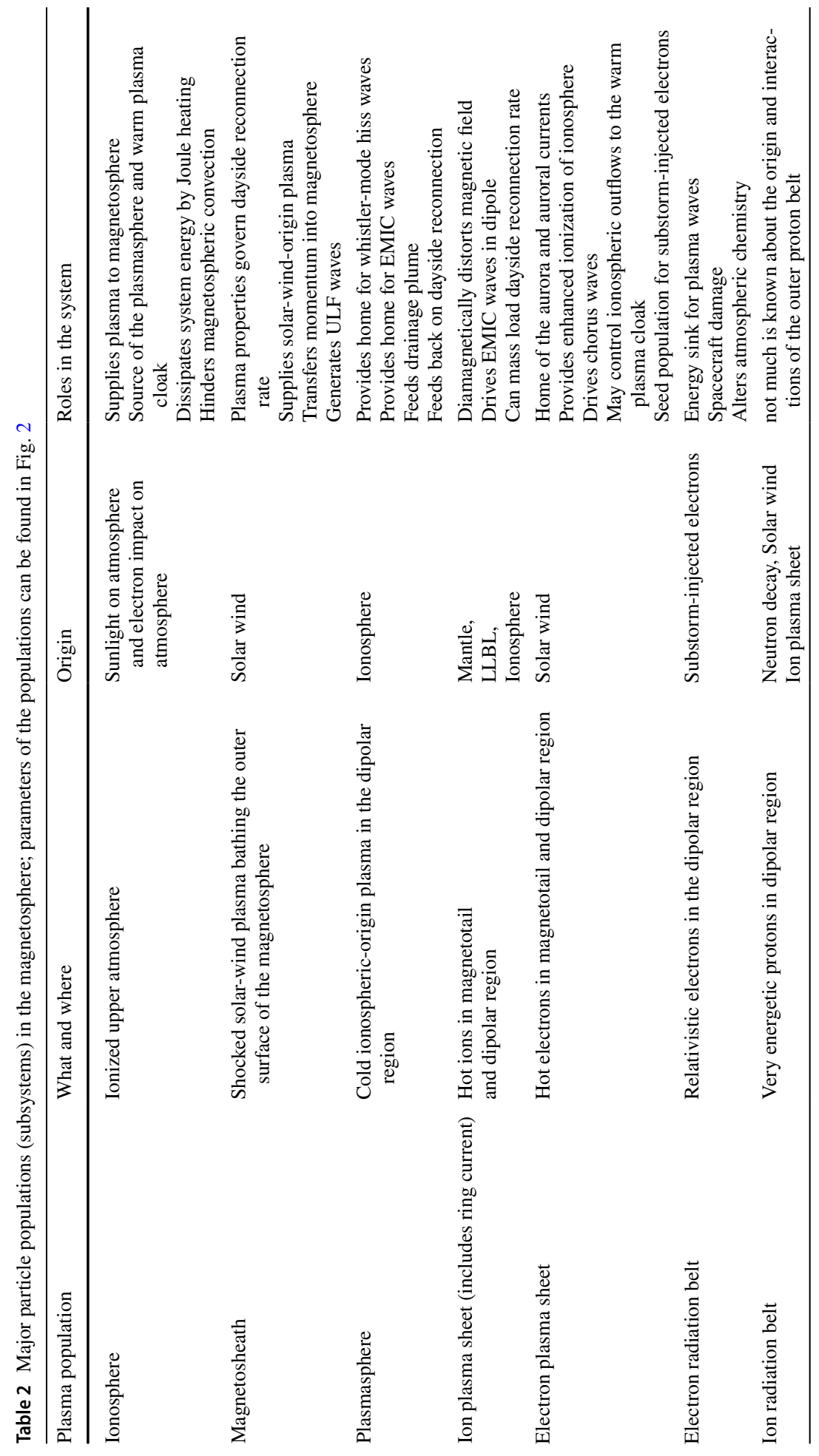




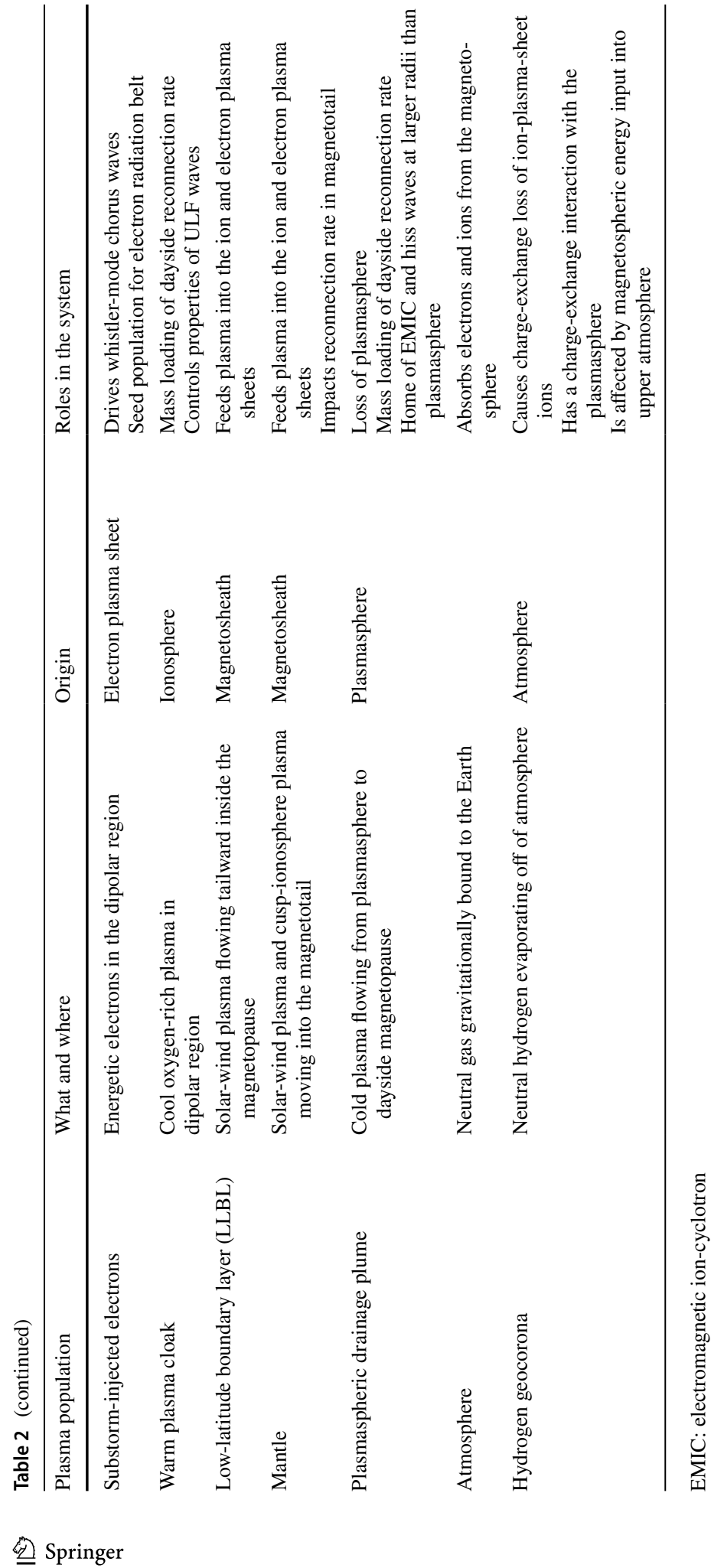


control which plasma waves can exist in this geographic region of the magnetosphere; consequently, the plasmasphere controls a lot of the interactions between other plasmas. For a geographic sketch of the location of the plasmasphere in the magnetosphere, see Fig. 1 of Borovsky (2014a).

The ion plasma sheet (Denton and Borovsky 2009) is a hot low-density plasma, typically of solar-wind origin, but becoming rich in $\mathrm{O}^{+}$ions from the ionosphere when magnetospheric activity is high. Two likely pathways for the solar-wind plasma to enter into the magnetotail to form the ion plasma sheet are via the cusp-mantle and via the lowlatitude boundary layer. The ion plasma sheet flows from the magnetotail into the nightside outer-dipolar region following magnetic-field convection. As the ion plasma sheet flows into the dipole magnetic field, magnetic drifts become important for those hot ions and the flow deviates strongly from the magnetic-field convection pattern. An important loss mechanism for the ion plasma sheet is charge exchange with the hydrogen geocorona; of the ion-plasma-sheet ions that do not charge exchange, most flow out the dayside of the magnetosphere, but some of the hot ions can be trapped in the dipole magnetic field. The ion plasma sheet is synonymous with the "ring current" and the "partial ring current." The plasma pressure of the ion plasma sheet can produce significant internal distortions to the dipole magnetic field of the magnetosphere. The ion plasma sheet is an important free energy source for plasma waves. The buildup of ionospheric oxygen in the ion plasma sheet can give the plasma sheet a high mass density: at those times the ion plasma sheet can alter the rate of reconnection on the dayside magnetopause. We will discuss the electrons of the plasma sheet separately from the ions of the plasma sheet, denoting them as two separate plasma populations: in the magnetotail they are colocated, but in the dipolar portions of the magnetosphere they have different convection paths. For a geographic sketch of the location of the ion plasma sheet in the magnetosphere, see Fig. 1 of Borovsky et al. (1997).

The electron plasma sheet (Elphic et al. 1999) is a hot low-density population of electrons that begins in the magnetotail like the ion plasma sheet. The electron plasma sheet convects sunward from the magnetotail into the outer dipole carried by magnetic-field convection. Unlike the hotter ions, the electron-plasma-sheet electrons follow the magneticfield convection in the dipolar region. In the dipolar region, the plasma-sheet electrons convect toward the dayside magnetopause, where they will be lost from the system. On the way to the dayside magnetopause, the electrons suffer heavy pitch-angle-scattering losses to the atmosphere as they pass through the dipolar region. The electron plasma sheet is a free energy source for plasma waves, it is the electron source for substorm-injected electrons, and it is the magnetospheric location of the aurora. The warm plasma cloak is colocated with the electron plasma sheet in the dipolar region of the magnetosphere; it is likely that the electron plasma sheet (perhaps via auroral processes) drives the ionospheric outflows that produce the warm plasma cloak. For a geographic sketch of the location of the electron plasma sheet in the magnetosphere, see Fig. 5 of Thomsen et al. (1998).

The electron radiation belt (Friedel et al. 2002) is a population of very-high-energy (even relativistic) electrons orbiting in the dipolar portion of the magnetosphere. The electron radiation belt is divided into an inner belt close to the Earth and an outer belt further away. The seed population for the electron radiation belt is probably substorm-injected electrons. The radiation-belt electrons are energized by electromagnetic plasma waves in the dipolar magnetosphere. There are two major loss mechanisms: (1) pitch-angle scattering by plasma waves into the Earth's atmosphere and (2) outward diffusion to the magnetopause. Intensifications of the radiation belt pose a hazard to spacecraft that are orbiting the Earth. The precipitation of radiation-belt electrons into the atmosphere can impact the chemistry of the middle atmosphere $\left(\mathrm{NO}_{\mathrm{x}}, \mathrm{HO}_{\mathrm{x}}\right.$, and ozone) and the ionization and 
electrical conductivity of the middle atmosphere. For a geographic sketch of the location of the electron radiation belt in the magnetosphere, see Fig. 9 of Lyons et al. (1972).

The ion radiation belt (Borovsky et al. 2016) is a population of very-high-energy protons orbiting in the dipolar portion of the magnetosphere. Much less is known about the dynamics of the ion radiation belt than is known about the electron belt. There are two known sources for the ion radiation belt: (1) the decay of neutrons off the top of the atmosphere into protons and electrons and (2) the capture of energetic protons from the solar wind by the magnetosphere. A third potential source is the ion plasma sheet, particularly after substorm energization (Birn et al. 1997). For a geographic sketch of the location of the proton radiation belt in the magnetosphere, see Plate 1 of Beutier et al. (1995).

Substorm-injected energetic electrons (Birn et al. 1998) are energetic electrons delivered from the magnetotail into the dipolar region by substorms. A substorm is a brief interval ( $30 \mathrm{~min})$ of very intense earthward convection of magnetic flux from the magnetotail into the nightside dipolar region. As magnetospheric convection brings plasma earthward from the tail, the plasma is squeezed and energized. Normally, the hottest electrons of the magnetotail electron plasma sheet do not convect into the dipole owing to the dominance of magnetic drifts on the energetic electrons. However, substorm convection is unusually strong and the substorm can deliver a surge of those hot electrons into the dipole before the magnetic drifts affect them. These substorm-injected energetic electrons provide free energy for the growth of waves and probably serve as the seed population for the electron radiation belt. Substorm-injected electrons reside in the dipolar region for only a few hours after a substorm occurs, eventually being pitch-angle scattered into the atmosphere where they are lost. The precipitation of substorm-injected electrons into the atmosphere affects ionospheric conductivity and affects atmospheric chemistry and ionization.

The warm plasma cloak (Chappell et al. 2008) is an oxygen-rich population of 10s of $\mathrm{eV}$ ions (warmer than the plasmasphere) seen throughout the outer portions of the dipolar magnetosphere colocated with the electron-plasma-sheet population. The origin of the cloak is the ionosphere. Very little survey work has been done to characterize the warm plasma cloak and its time-varying properties. The warm plasma cloak influences the properties of plasma waves in the dipolar magnetosphere, particularly ULF waves. The high mass density of the cloak can have an influence on the dayside reconnection rate; hence, it may influence the amount of solar-wind driving of the magnetosphere. For a geographic sketch of the location of the warm plasma cloak in the magnetosphere, see Fig. 16 of Chappell et al. (2008).

The low-latitude boundary layer (Nemecek et al. 2015) is a mixture of hot magnetospheric plasma and hot magnetosheath plasma that resides just inside the magnetopause. It flows anti-sunward (in the direction of solar-wind flow) inside the magnetosphere. The low-latitude boundary layer is believed to be a pathway for solar-wind plasma (magnetosheath) to be delivered into the magnetotail to form the plasma sheet. For a geographic sketch of the location of the low-latitude boundary layer in the magnetosphere, see Fig. 3 of Reiff et al. (1994).

The mantle (Siscoe and Sanchez 1987) is a cool, anti-sunward-flowing plasma inside the magnetopause in the high-latitude (northern and southern) regions of the magnetosphere, particularly in the magnetotail. The mantle is magnetosheath plasma that enters into the magnetosphere in the northern and southern cusps. The mantle is another pathway for solar-wind plasma to enter into the magnetotail to form the plasma sheet. The mantle may also play a role in altering reconnection rates in the magnetotail (Hesse and Birn 2004). For a geographic sketch of the location of the mantle in the magnetosphere, see Fig. 1 of Eastwood et al. (2015). 
The plasmaspheric drainage plume (Borovsky and Denton 2008) is a narrow band of cold, dense plasmaspheric plasma convecting sunward from the plasmasphere in the inner dipolar region to the dayside magnetopause, where it is lost from the magnetosphere. The drainage plume occurs during geomagnetic storms. The plume puts dense plasmaspheric plasma into the outer-dipolar regions; specific types of plasma waves can live in the dense drainage-plume plasma; and the plume allows those waves to exist in the outer-dipolar regions during storms. These waves in the plume have consequences for the evolution of the electron radiation belt. The dense plume plasma can also act to reduce the all-important dayside reconnection rate. For a geographic sketch of the location of the plasmaspheric drainage plume in the magnetosphere, see Fig. 1 of Borovsky (2014a).

The Earth's atmosphere (thermosphere and mesosphere; Turunen et al. 2009) acts to absorb electrons and ions from the magnetosphere that manage to hit it, removing them from the magnetospheric system. Neutral winds in the upper atmosphere can force convection in the ionosphere and can alter magnetosphere-ionosphere coupling (Richmond and Matsushita 1975; Lu et al. 1995). Two well-established impacts on the atmosphere are (1) energetic-electron precipitation from the electron radiation belt and from substorminjected electrons affecting the chemistry of $\mathrm{NO}_{\mathrm{x}}, \mathrm{HO}_{\mathrm{x}}$, and ozone in the middle atmosphere (Rodger et al. 2010; Andersson et al. 2012; Verronen et al. 2013; Seppala et al. 2015) and (2) energetic-electron precipitation from the electron radiation belt affecting the ionization and electrical conductivity of the middle atmosphere (Rycroft et al. 2000; Rodger et al. 2007; Borovsky 2017a). The Joule heating of the ionosphere associated with magnetospheric activity produces temperature changes in the upper atmosphere which change the atmospheric height profile and change the upper-atmospheric neutral winds (Fuller-Rowell et al. 1994; Burns et al. 2004; Wang et al. 2008; Lei et al. 2010; Weimer et al. 2013).

The neutral-hydrogen geocorona (exosphere; Ostgaard et al. 2003) is not a plasma; rather, it is a cloud of neutral-hydrogen atoms evaporating off the top of the upper atmosphere into the magnetosphere. Ions of the magnetosphere can charge exchange in the cloud of neutral hydrogen, changing an energetic ion into a very-low-energy ion. The geocorona provides an important loss for ion-plasma-sheet ions. Because of an energy dependence to the charge-exchange cross section, and because ions of different energies drift deeper into the geocorona, the charge-exchange losses produced by the geocorona can lead to free energy in the ion plasma sheet that can drive plasma waves (Thomsen et al. 2017). Magnetospheric activity produces observed alterations in the radial profile of the geocorona via changes in the charge exchange with the activity-dependent plasmasphere and via changes in the thermospheric temperature driven by magnetospheric Joule heating (Bailey and Gruntman 2013; Qin et al. 2017; Kuwabara et al. 2017). For a images of the location of the hydrogen geocorona, see Fig. 2 of Kameda et al. (2017).

In the third column of Table 2, the origins of each of the particle populations are listed. Each population is distinct in properties (cf. Fig. 2) and location, but in the magnetospheric system one population feeds another population with various physical mechanisms acting to transform the particles of one population into another. In general, the transformation involves heating (energization). (The exception to this heating is the production of the mantle from magnetosheath plasma.) To illustrate the transformation of populations, in Fig. 3 the evolutionary pathways of the ion populations that produce the ion plasma sheet are sketched, with the different particle populations represented as square boxes and physical processes represented as ovals. Starting at the top of the sketch, solar-wind plasma is transformed into magnetosheath plasma when the solar-wind plasma passes through the bow shock. The magnetosheath bathes the magnetosphere and can enter into the cusps to become the mantle plasma, and it can cross the magnetopause to become the low-latitude 


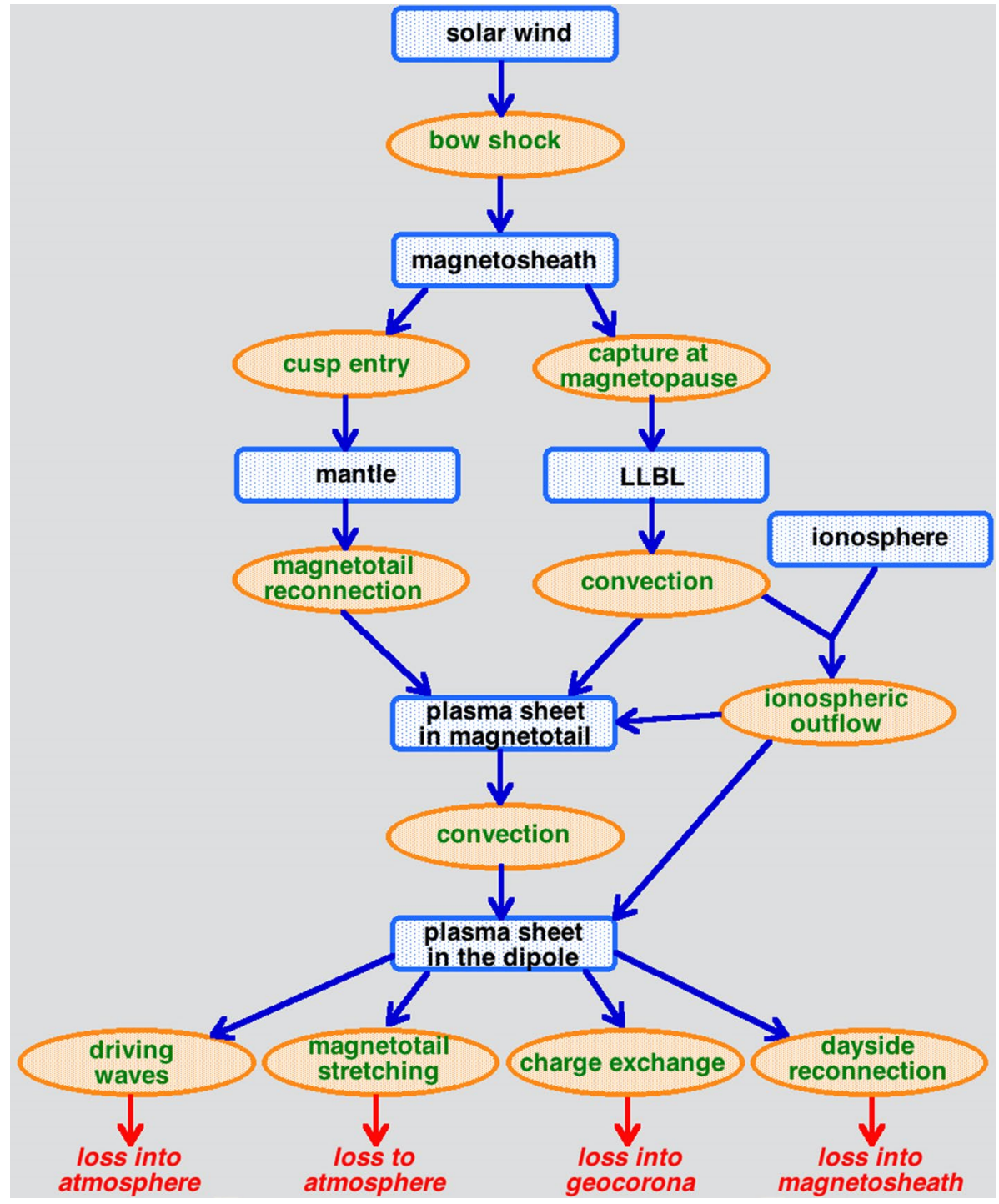

Fig. 3 A sketch of the evolution of ion populations that eventually produce the ion plasma sheet, and the various ways in which the ion plasma sheet is lost from the magnetospheric system

boundary layer (LLBL) plasma. The mantle plasma is transformed and enters into the ion plasma sheet in the magnetotail via the process of magnetic reconnection in the magnetotail; simultaneously, magnetospheric convection brings LLBL plasma into the magnetotail to join the ion plasma sheet. Additionally, if magnetospheric convection is strong, it leads to ion outflow from the ionosphere adding $\mathrm{O}^{+}$ions to the ion plasma sheet. Magnetospheric convection delivers plasma sheet ions from the magnetotail into the nightside of the dipolar region of the magnetosphere. In the dipolar region, a number of loss mechanisms act, as noted at the bottom of the sketch of Fig. 3: the ion plasma sheet drives plasma 
waves that scatter its ions into the atmosphere, magnetotail stretching acts to scatter ions into the atmosphere, and charge-exchange collisions with the neutral-hydrogen geocorona remove the hot ion-plasma-sheet ions from the system. Finally, if the ions pass through the dipolar region to the dayside magnetopause, they are lost into the magnetosheath via dayside reconnection.

\section{Important Types of Plasma Waves and What They Do}

Plasma waves are electromagnetic fluctuations in a plasma. The waves are characterized by frequency, by wavelength, and by the wave-vector direction with respect to the magneticfield direction. Plasma waves can interact with the electrons in a plasma, with the ions in a plasma, or with the bulk parameters of the plasma such as density and velocity. Plasma waves do much of the coupling between the subsystems in the magnetosphere: typically one subsystem will create the waves and a second subsystem will be affected by the waves. In this sense, much of the plasma-wave coupling is "one way" with subsystem A affecting subsystem B, but not vice versa. Some of the most important types of plasma waves are collected into Table 3 and discussed below.

ULF waves (Takahashi and Anderson 1992) are few-minute-period waves in the dipolar magnetosphere. They can be driven by a number of mechanisms: (1) by solar-winddriven Kelvin-Helmholtz waves on the magnetopause, (2) by time-varying compressions of the dayside magnetosphere caused by time-varying properties of the solar-wind plasma, and (3) by free energy in the ion plasma sheet. ULF waves produce a radial diffusion of radiation-belt electrons and ions that redistribute the belt populations and can lead to loss of radiation-belt particles across the magnetopause. The redistribution also produces some energization of the radiation-belt electrons. The ULF waves mediate a coupling between the solar wind, the ion plasma sheet, and the ion and electron radiation belts.

$E M I C$ (electromagnetic ion-cyclotron) waves (Usanova et al. 2012) are driven by free energy (such as thermal anisotropy) in the ion-plasma-sheet population. The dense plasmasphere and plume control where they can exist, and they are most prevalent where the ion plasma sheet and the plasmasphere/plume spatially overlap. EMIC waves are important for pitch-angle scattering ion-plasma-sheet ions and radiation-belt electrons into the atmosphere, removing them from the system. EMIC waves mediate a coupling between the ion plasma sheet and the electron radiation belt, with the plasmasphere influencing this coupling.

Whistler-mode waves (Stenzel 1999) are waves at audible frequencies that interact mainly with electrons. The whistler-wave activity is separated into two types: chorus (where individual temporal bursts of wave activity can be detected) and hiss (where wave activity is temporally continuous; Santolik and Chum 2009). (The reader can listen to the two types at http://www.astrosurf.com/luxorion/audiofiles-geomagnetosphere.htm). The local presence or absence of dense plasmaspheric plasma often determines which of the two types will be present.

Whistler-mode chorus waves (Meredith et al. 2003; Kasahara et al. 2018) are found in the dipolar region outside of the plasmasphere and drainage plume. These waves are driven by free energy in the electron-plasma-sheet population and the substorm-injectedelectron population. They are particularly robust after a substorm occurs. Whistler-mode chorus waves are important for energizing radiation-belt electrons and for pitch-angle scattering radiation-belt electrons and plasma-sheet electrons into the atmosphere, removing 


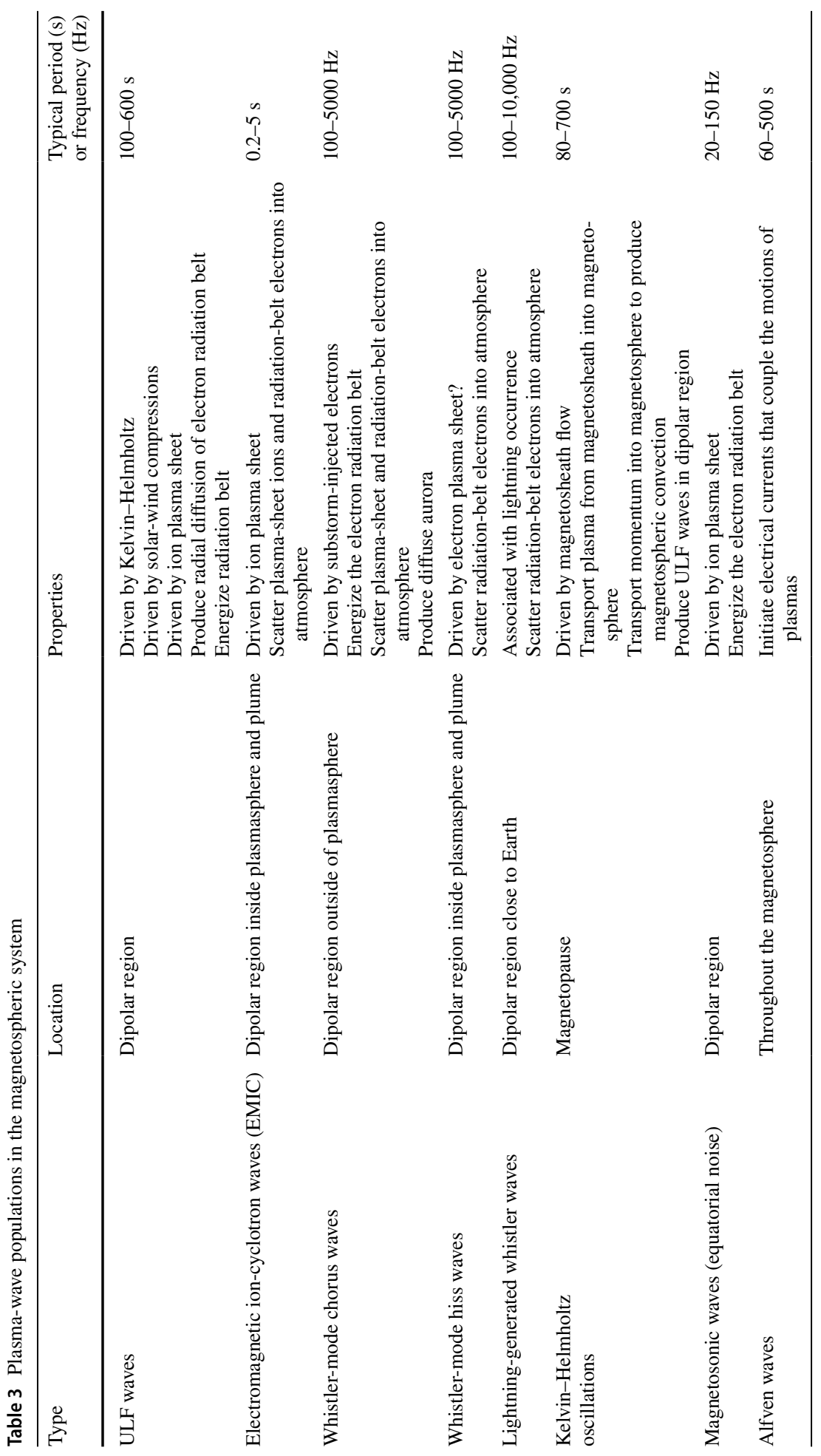


them from the system. The whistler-mode scattering of electrons into the atmosphere produces the "diffuse aurora." Whistler-mode chorus mediates a coupling between the electron plasma sheet and the electron radiation belt, with the plasmasphere influencing this coupling.

Whistler-mode hiss (Bortnik et al. 2011) is found in the dipolar region inside of the plasmasphere and drainage plume. At present, it is a controversy whether (a) whistlermode hiss waves inside the plasmasphere are the result of whistler-mode chorus waves that propagate into the plasmasphere from outside or (b) whistler-mode hiss waves are directly driven by energetic electrons. Whistler-mode hiss is important for pitch-angle scattering radiation-belt electrons into the atmosphere. Whistler-mode hiss mediates a coupling between the plasmasphere and the electron radiation belt, with the electron plasma sheet playing a role in the coupling.

Lightning-generated whistlers (Oike et al. 2014) are found in the dipolar region very close to Earth. Their presence in the magnetosphere is associated with the intensity of thunderstorm activity in the atmosphere. Scattering of radiation-belt electrons into the atmosphere by lightning-generated whistler waves is a minor contributor to radiation-belt loss (Rodger et al. 2003).

Kelvin-Helmholtz waves (Nykyri and Otto 2001) are low-frequency propagating ripples on the magnetopause driven by the wind shear between the strongly flowing magnetosheath plasma and the slowly flowing magnetospheric plasma. They are akin to the ripples on a flag in the wind. Kelvin-Helmholtz waves are important for transporting magnetosheath plasma into the magnetosphere and for transporting momentum into the magnetosphere. The Kelvin-Helmholtz waves on the magnetopause also drive ULF waves inside the dipolar region of the magnetosphere, with those ULF waves affecting the radiation belts.

Magnetosonic waves (also known as "equatorial noise"; Santolik et al. 2016; Min et al. 2018) are medium-frequency waves in the dipolar region driven by free energy in the ion plasma sheet, with the waves intensifying when a substorm occurs. Magnetosonic waves interact with radiation-belt electrons to energize those electrons.

Alfven waves (Keiling 2009) are low-frequency electromagnetic waves whose propagation is ducted (focused) along the magnetic-field lines of the magnetosphere. Alfven waves are very important for establishing magnetic-field-aligned electrical currents that transport energy and deliver electromagnetic forces long distances along the magnetic-field lines. Such current systems (initiated by Alfven waves (Goertz and Boswell 1979)) couple magnetospheric convection to the ionospheric convection (Lysak 1990) and, in the polar regions, couple the flowing magnetosheath plasma to the polar ionosphere (Wright 1996). The auroral currents are also initiated with Alfven waves propagating from the plasma sheet in the magnetosphere to the ionosphere (Vogt 2002).

\section{Types of Activity in the Magnetospheric System}

Often when magnetospheric activity is discussed in the research literature, what is specifically meant is geomagnetic activity (Rostoker 1972) as measured by one of several geomagnetic indices that are readily available. Each geomagnetic index is constructed of measurements from ground-based magnetometers, and each index is a measure of the intensity of a particular magnetosphere-ionosphere electrical current system. Hence, an increase in geomagnetic activity is the intensification of some current system in the magnetosphere. 
Here we will go much further: we will describe the various aspects of magnetospheric activity, as listed in Table 4.

The dayside reconnection rate (Komar and Cassak 2016) is the rate at which the magnetic field of the moving solar-wind plasma becomes connected to the Earth's magnetic

Table 4 Types of activity in the magnetospheric system

\begin{tabular}{ll}
\hline Type & Explanation \\
\hline Geomagnetic activity & $\begin{array}{c}\text { The intensification of one of several current systems in the magneto- } \\
\text { sphere that can be measured by ground-based magnetometers }\end{array}$ \\
Dayside reconnection rate & $\begin{array}{l}\text { Creation of magnetic connection between solar-wind plasma and the } \\
\text { magnetosphere. Highly time variable with solar-wind time variations. } \\
\text { Controls the amount of driving of the magnetosphere by the solar } \\
\text { wind }\end{array}$
\end{tabular}

Magnetotail growth/polar-cap size Dayside reconnection adds magnetic flux into the magnetotail increasing the magnetic energy of the magnetospheric system

Magnetospheric convection

Transport of magnetic flux and plasma from the magnetotail into the dipolar region and then to the dayside magnetopause

Ionospheric convection

Horizontal transport of plasma from the dayside of the Earth to the nightside over the polar cap with lower-latitude return flows to the dayside

Magnetotail stretching

Intensification and earthward expansion of a cross-tail electrical current as flux is loaded into the magnetotail and as magnetospheric convection intensifies

Substorm occurrence

Large-scale morphological instability of the magnetotail. Produces enhanced transport in magnetosphere, injects energetic particles into dipolar region, greatly increases energy dissipation, is driver of enhanced auroral currents and particle precipitation

Global sawtooth oscillations

Large-scale morphological instability of the entire magnetosphere, dayside as well as nightside

Auroral currents

Field-aligned currents flowing between the nightside magnetosphere and the nightside ionosphere. Important for Joule dissipation of electromechanical energy

Auroral particle precipitation

Dissipation of magnetospheric energy. Produces localized enhanced electrical conductivity of the ionosphere

Ionospheric outflow

Upflow of ions into the magnetosphere in the cusp and auroral regions. Essential to build magnetospheric plasma populations. Eventually impacts dayside reconnection rate

Ring-current enhancement

Diamagnetic distortion of the dipolar magnetosphere caused by the particle pressure of the ion plasma sheet as the plasma-sheet population intensifies and moves into the dipole

Radiation-belt dropout

Sudden weakening of the intensity of the electron radiation belt in the early phases of a storm. Temporally correlated with an increase in solar-wind ram pressure

Radiation-belt intensification

Slow energization of the electron radiation belt during intervals of sustained magnetospheric driving by the solar wind

Storm

A strong elevation of all measures of magnetospheric activity associated with a feature in the solar wind that produces very strong driving of the magnetosphere. Two major types of storms: coronal-massejection-driven and high-speed-stream-driven

Calm before the storm

Prior to most high-speed-stream-driven storms, there is a few-day period of anomalously low magnetospheric activity caused by a feature in the solar wind prior to the high-speed stream 
field. In a sense, it is the number of magnetic-field lines per unit time in the solar wind that become connected to the Earth. The dayside reconnection rate largely controls the amount of solar-wind driving of the magnetospheric system, and so the dayside reconnection rate largely controls all forms of magnetospheric activity. The properties of the solar wind vary with time, so the reconnection rate varies with time, with great variations in solar-wind parameters producing great variations in the reconnection rate. A particularly fast variation is caused by the sensitivity of the reconnection rate to the orientation of the magnetic-field vector in the solar-wind plasma, which varies on timescales of minutes. Note that there are time lags (minutes to days) between the reconnection rate and the various responses of the magnetospheric system.

Magnetotail growth (Petrinec and Russell 1996) results from dayside reconnection allowing the flowing solar wind to pull magnetic-field lines from the dayside magnetosphere and lay them down into the magnetotail, increasing the cross-sectional size of this cylindrical tail of field lines that are connected to the Earth. The polar-cap size (Huang et al. 2009) is directly related to the amount of magnetic flux in the magnetotail. Magnetotail growth represents an accumulation of magnetic energy that can be released by magnetic-field-line reconnection occurring in the tail. Reconnection in the tail allows magnetic-field lines to be transferred sunward back to the dayside magnetosphere, setting up magnetospheric convection. When magnetotail growth becomes substantial, a global magnetic instability of the magnetotail can occur to produce a substorm.

Magnetotail stretching (Gvozdevsky and Sergeev 1996) occurs during magnetotail growth: as more magnetic flux is added to the tail, a dawn-to-dusk horizontal sheet of current across the center of the magnetotail (separating the north half from the south half) intensifies and this current sheet spreads earthward. As the current sheet moves into the nightside dipole, it changes the near-Earth magnetic-field morphology from dipole-shaped field lines into magnetotail-morphology field lines.

Magnetospheric convection (Tanaka 2007) is the result of the transport of magnetic flux over the poles from the dayside magnetosphere into the magnetotail and the return of that magnetic flux through the magnetosphere from the tail to the dayside. Plasma is transported along with this magnetic convection, and the plasma is compressed and heated as it is brought in from the magnetotail. Magnetospheric convection sets up global electrical current systems in the magnetosphere that distort the morphology of the magnetic field and that give rise to the aurora.

Ionospheric convection (Weimer 2005) follows magnetospheric convection. As magnetic-field lines are carried by the solar wind over the poles from the dayside to the nightside after reconnection on the dayside, the footprints of those magnetic-field lines where they connect to the Earth are pulled toward the magnetotail. This pulling sets up a global flow of the ionospheric plasma from the dayside toward the nightside in the Earth's polar regions. Consistent with the flow of magnetic-field lines returning from the magnetotail through the dipolar region to the dayside, there is a return flow in the ionosphere at lower latitudes from the nightside to the dayside.

A substorm (McPherron et al. 1973) is a short-lived surge in earthward convection in the magnetotail accompanied by a global change in the magnetic morphology of the tail, representing a transfer of stored magnetic energy into flow kinetic energy and plasma heating. The morphology change in the near-Earth nightside region is a return to a dipolar magnetic-field configuration from a tail configuration. Substorms deliver energetic substorm-injected electrons into the dipolar region, produce great increases in plasma-wave activity, and produce great increases in auroral activity. Substorms can 
occur randomly (associated with randomly occurring intervals of enhanced solar-wind driving) or they can occur periodically with recurrence periods of about $3 \mathrm{~h}$.

Global sawtooth oscillations (Borovsky 2004) are periodic $(\sim 3 \mathrm{~h})$ events wherein there is a magnetic-field stretching that occurs all around the Earth (dayside and nightside) followed by a sudden substorm-like magnetic-morphology change all around the earth. Global sawtooth oscillations occur during some types of magnetic storms.

Auroral currents (Strangeway 2012) are electrical currents that flow along magneticfield lines between the nightside magnetosphere and the high-latitude nightside ionosphere. These currents are associated with magnetospheric convection, and the intensity of the currents increases when solar-wind driving increases. There are also substantial increases in the auroral currents when a substorm occurs. The currents produce a Joule dissipation of energy in the ionosphere, with that energy being extracted from the magnetosphere.

Auroral particle precipitation (Newell et al. 2016) produces diverse forms of optical airglow caused by magnetospheric particles hitting the upper atmosphere. Some types of aurora (e.g., auroral arcs) are associated with electron acceleration in electrical current systems in the nightside magnetosphere, and some types (e.g., diffuse aurora) are associated with the pitch-angle scattering of magnetospheric electrons and protons into the atmosphere. The auroral particle precipitation is an important loss mechanism for plasma-sheet electrons and the precipitation produces important changes in the electrical conductivity of the ionosphere. When the driving of the magnetosphere by the solar wind increases, auroral airglow intensities increase.

The ionospheric outflow of ions (Welling et al. 2015), particularly $\mathrm{O}^{+}$, increases as the driving of the magnetosphere by the solar wind increases. Ionospheric outflow has different properties coming from different regions of the Earth: e.g., the polar caps, the sunlit dayside, the nightside auroral zone. Various mechanisms act to push the ionospheric ions upward against gravity to produce the outflows, and these mechanisms may be strengthened by ionospheric convection and by magnetospheric particles hitting the upper atmosphere.

Ring-current enhancement (Liemohn et al. 2001) is caused by an increase in the plasma-sheet pressure in the dipolar magnetosphere, which is caused by sustained strong levels of magnetospheric convection. The pressure of the plasma-sheet ions in the dipole is associated with a diamagnetic current that distorts the magnetic morphology of the dipolar region.

Radiation-belt dropouts (Onsager et al. 2007) are rapid reductions of the number of radiation-belt electrons in the dipolar region of the magnetosphere. The dropouts are associated with intervals when the solar-wind number density becomes unusually high. In a dropout, the number density of the outer portions of the electron radiation belt can drop by one or two orders of magnitude in a few hours. The dropouts tend to occur in the early phases of a storm. The dropouts usually last for a fraction of a day.

Radiation-belt intensifications (Blake et al. 1997) occur in the outer portions of the electron radiation belt during long-duration (days) intervals of high magnetospheric activity. The sustained driving of plasma waves in the magnetospheric system leads to a steady energization of radiation-belt electrons by wave-particle interactions, producing a hotter and hotter radiation belt day after day.

A magnetospheric storm (Gonzalez et al. 1994) is an interval (a few hours to several days) wherein greatly enhanced driving of the magnetosphere by the solar wind produces greatly enhanced activations of magnetospheric phenomena. Storms can be identified with large-scale features in the solar wind plasma: hence, two major types of storms are magnetic-cloud-driven storms and high-speed-stream-driven storms (Borovsky and 
Denton 2006). These two types of storms exhibit systematically different magnetospheric phenomena.

The calm before the storm (Borovsky and Steinberg 2006) is a few-day-long interval of extremely quiet magnetospheric activity that tends to occur just prior to the occurrence of a high-speed-stream-driven storm. The extended calm interval can precondition the magnetosphere for the upcoming storm.

\section{Emergent Phenomena}

In this section, we will discuss four examples of emergent phenomena in the magnetosphere, listed in Table 5. Here we will take the definition of "emergence" to be: "Emergence is the phase when new organizations and functions arise from the interactions of smaller, less complicated entities" (Mobus and Kalton 2015, p. 504). The connection of these entities has new consequences for the working of the system.

The first example is auroral arcs (Borovsky 1993). An auroral arc is a long (1000s of $\mathrm{km}$ ) east-west aligned thin (1-10 km) vertical curtain of airglow in the high-latitude nightside upper atmosphere. The airglow is caused by the impact of magnetospheric electrons that are accelerated downward into the atmosphere along magnetic-field lines that connect into the electron plasma sheet. The arcs are spatially colocated with electrical currents that flow between the magnetosphere and the ionosphere. The auroral currents dissipate electrical energy in the ionosphere and the accelerated electrons deposit energy in the atmosphere, with all of the energy coming from the magnetosphere. The amount of power extracted from the magnetosphere by auroral arcs is significant and must have an impact on the evolution of the magnetotail and the evolution of the ion and electron-plasma-sheet populations. When the solar wind is not driving the magnetosphere, auroral arcs are weak to absent. When solar-wind driving increases, the intensity of the auroral arcs and auroral currents increases, with about a 1-h time lag from the driving. One of the major unknowns of magnetospheric physics is the identity of the physical mechanisms in the magnetosphere that produce auroral arcs: it is likely that arcs are associated with magnetospheric convection and with the evolution of the plasma sheet ions and electrons in that convection. In

Table 5 Four examples of emergent phenomena in the Earth's magnetospheric system

\begin{tabular}{lll}
\hline Phenomenon & Directly interacting subsystems & Necessary magnetospheric activity \\
\hline Auroral arcs & $\begin{array}{l}\text { Ion plasma sheet } \\
\text { Electron plasma sheet } \\
\text { Ionosphere }\end{array}$ & Magnetospheric convection \\
Pulsating-aurora patches & $\begin{array}{l}\text { Electron plasma sheet } \\
\text { Ion plasma sheet } \\
\text { Ionosphere }\end{array}$ & Substorms \\
& Electron plasma sheet & \\
Substorms & Ion plasma sheet & Magnetotail growth \\
& Electron plasma sheet & \\
The electron radiation belt & Ion plasma sheet & Substorms \\
& Substorm-injected electrons & \\
& Plasmasphere & \\
& Magnetosheath & \\
& Geocorona & \\
\end{tabular}


order for auroral arcs to occur, several things must happen in the magnetospheric system. (1) Dayside reconnection must occur to enable the solar wind to load magnetic flux into the magnetotail. (2) Magnetospheric convection must occur and the electron and ion plasma sheets must evolve to create free energy to drive auroral electrical currents. (3) Some mechanism in the magnetosphere must act to drive the electrical current from the electron plasma sheet into the ionosphere. (4) Some mechanism must act to extract power from the ion plasma sheet and/or the electron plasma sheet to supply the auroral current system. (5) Some mechanism in the current system must act to accelerate the magnetospheric electrons into the atmosphere. (6) There must be a conducting ionosphere to close the electrical current, whose conductivity is enhanced locally by the impact of the electrons, probably nonlinearly.

The second example of an emergent phenomenon is pulsating-aurora patches (Jaynes 2018). Pulsating aurora appear in the high-latitude upper atmosphere after a substorm occurs. To an observer on the ground, the pulsating aurora appear as a set of optically blinking horizontal patches in the sky (blink periods $\sim 1 \mathrm{~s}$ ) at an altitude of about $100 \mathrm{~km}$, slowly drifting horizontally relative to the ground observer. The patches each blink on and off periodically, with the individual patches blinking independently (Scourfield et al. 1972) and with different blink rates (Nishiyama et al. 2012). Typical patch horizontal sizes are 10 s to $100 \mathrm{~s}$ of $\mathrm{km}$ in the upper atmosphere (Royrvik and Davis 1977), with a tendency to be east-west elongated, with a patch lifetime of up to 10s of minutes (Grono et al. 2017). It is currently believed that the pulsating aurora is caused by the pitch-angle scattering of plasma-sheet electrons into the upper atmosphere by high-frequency $(\sim \mathrm{kHz})$ whistlermode-chorus waves in the dipolar region of the magnetosphere outside of the plasmasphere. Unknowns are (a) what determines the shape of the patches, (b) what governs the drift of the patches, and (c) why the pitch-angle scattering turns on and off with a fewsecond periodicity. A number of things have to happen in the system for pulsating aurora to occur. (1) There must be an electron plasma sheet. (2) A substorm must occur to put free energy into the electron plasma sheet for the chorus waves to grow. (3) There must be pitch-angle scattering of the electrons by the waves. (4) Something must act to turn the wave scattering on and off, perhaps lower-frequency waves (such as ULF waves or magnetosonic waves) that are driven by free energy in the ion plasma sheet. Spatial structure in cool plasma such as the warm plasma cloak may play a role in shaping the pulsating patches. The pulsating-aurora patches are the visualizations of "coherent structures" (Cross and Hohenberg 1993; Shalizi et al. 2006; Dawes 2010) that arise in the very-large-scale electron plasma sheet.

A third example of an emergent phenomenon is a substorm (McPherron et al. 1973). Substorms are associated with a slow buildup of magnetic energy in the magnetotail followed by a rapid reduction in that built-up magnetic energy as the substorm initiates. Substorms have been described as a global plasma instability of the magnetotail triggered by the onset of magnetic-field-line reconnection in the magnetotail when the cross-tail current sheet becomes too thin (Birn et al. 2004), with reconnection allowing the magnetotail to morphologically change into a lower energy state. Substorm occurrence has also been described as a consequence of self-organized criticality in the magnetotail (Klimas et al. 2000). In this case, it has been postulated that there is a continuous distribution of localized dissipation events, both in time and in space, some of which can sometimes naturally selforganize into a more global event (Uritsky et al. 2002). For a substorm to occur, several things must be happening in the system. (1) Dayside reconnection must occur. (2) The solar wind must carry the newly reconnected field lines over the poles of the Earth into the magnetotail. (3) There must be plasma in the magnetotail to enable a cross-tail current sheet to 
form to stabilize the magnetotail as it grows. (4) There must be plasma in the magnetotail to enable magnetic-field-line reconnection to suddenly disrupt the current sheet allowing a sudden release of magnetic energy. (5) Something (unknown at present) must act to stop the magnetic-field-line reconnection to terminate the substorm. Another related emergent phenomena may be the sudden appearance of energetic substorm-injected electrons in the dipolar region: those energetic electrons having new consequences for the system.

Fourth, the electron radiation belt (Thorne 2010) is probably the best example of an emergent phenomenon in the magnetospheric system, and it is itself an entire subsystem that emerges. If the radiation belt would not have been the first part of the magnetosphere to be discovered at the onset of the space age (e.g., Stern 1996), it would be difficult to predict its existence from even a modern reductionist understanding of the workings of the subsystems of the magnetospheric system. A great deal has to happen in the system to create the electron radiation belt (see also Fig. 4). (1) There must be (a) a dipolar portion to the magnetosphere so that very-high-energy electrons created can be trapped and (b) a magnetotail that can become globally unstable. (2) Energetic substorm-injected electrons must be repeatedly delivered into the dipolar magnetosphere by substorms to produce the seed-electron population for the radiation belt. (3) Substorms must continuously occur to put free energy into the electron plasma sheet to drive whistler-mode chorus waves. (4) Via

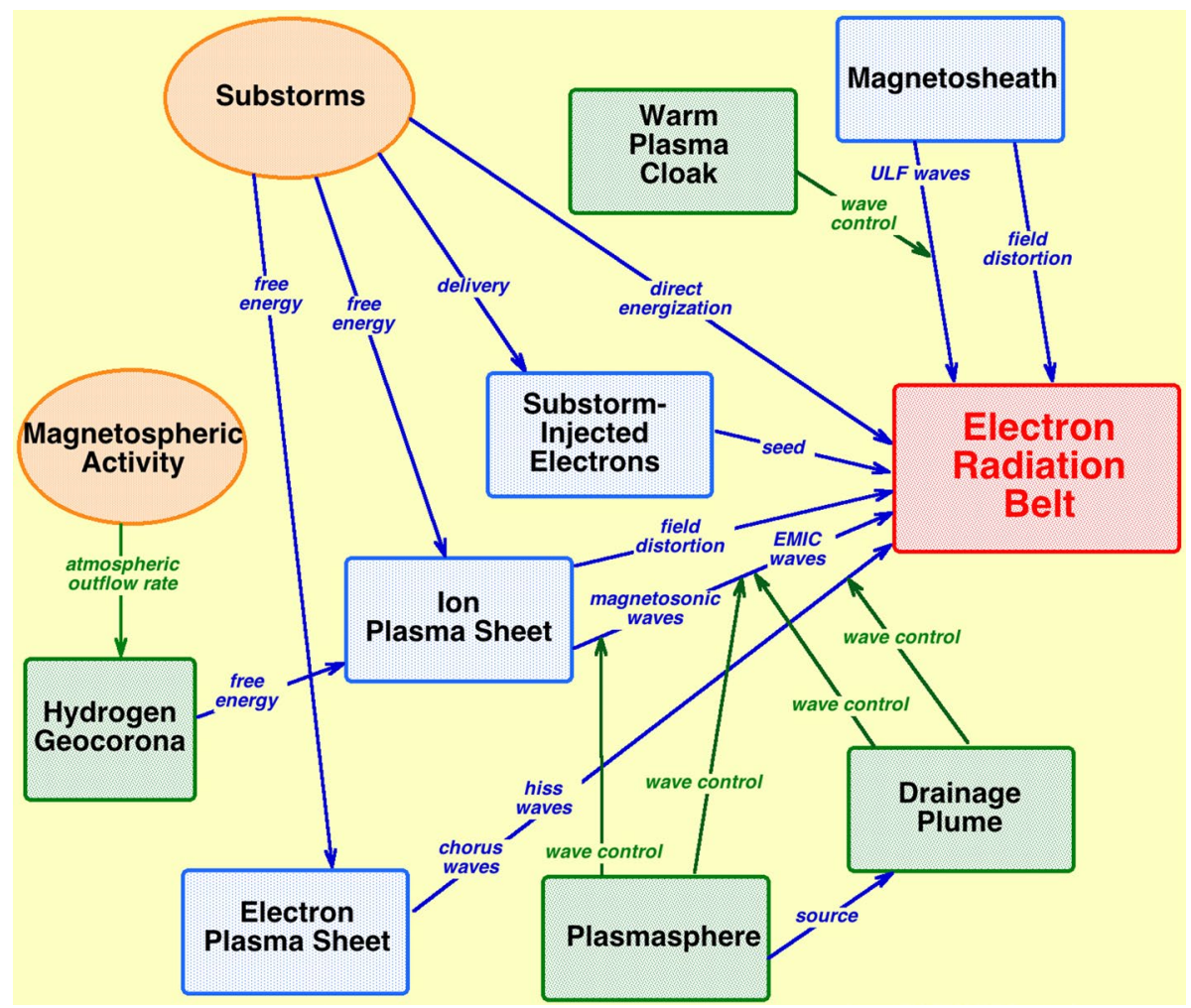

Fig. 4 A sketch of the connections needed to create and evolve the electron radiation belt (red box). Not included in the sketch are magnetic-field distortions by the formation of cross-tail current and the rapid distortion of the magnetosphere by interplanetary shock waves 
wave-particle interactions the whistler-mode chorus waves must energize the substorminjected electrons to very high energies. For the electron radiation belt to evolve, further processes must happen. (5) ULF waves must be created and the ULF waves must act to redistribute the radiation-belt via radial diffusion. (6) Whistler-mode hiss waves inside the plasmasphere must pitch-angle scatter the radiation-belt electrons into the atmosphere when the plasmasphere grows in radius during quiet magnetospheric activity. (7) ULF waves must radially diffuse the radiation-belt electrons outward during the early phases of storms to lose the electrons to the magnetopause to produce radiation-belt dropouts. (8) EMIC waves driven by the ion plasma sheet inside the plasmaspheric drainage plume must pitch-angle scatter the radiation-belt electrons into the atmosphere during the early phases of storms to help produce radiation-belt dropouts. Other system phenomena that are not depicted in Fig. 4 also play roles in the evolution of the electron radiation belt, including (a) magnetotail stretching, which distorts the dipole magnetic field and radially displaces the radiation belt, and (b) sudden distortions of the magnetic field by the passage of interplanetary shock waves in the solar wind, which is important for the evolution of the electron radiation belt close to the Earth. The electron radiation belt is born from substorm-injected electrons. If substorms are not occurring, there are no substorm-injected electrons in the dipolar region. After a substorm occurs, the injected electrons, with energies $\sim 100 \mathrm{keV}$, have lifetimes of only a few hours before they are pitch-angle scattered into the atmosphere. When those electrons are energized (by chorus waves and by ULF processes) to $\sim 1 \mathrm{MeV}$, they form a more-long-lived population and can reside in the outerdipolar region for many days (Meredith et al. 2006) and in the inner dipolar region for years (Stassinopoulos and Verzariu 1971).

\section{The Applicability of System Descriptors to the Magnetosphere}

Table 6 lists some of the systems science adjectives used to categorize and describe systems, and in Table 6 an assessment of each of those adjectives is given as it applies to the solar-wind-driven magnetosphere. An elaboration of that assessment is given in this section.

Adaptive The magnetosphere adapts strongly to its solar-wind environment, changing as the properties of the solar wind vary. There are multiple time lags in the reaction of the subsystems to the solar wind, from minutes (reaction of the global system to changes in the solar-wind pressure) to a few days (intensification of the electron radiation belt in response to sustained solar-wind driving). Note that there is an informative historic comparison between the reaction of the magnetospheric system to driving by the solar wind and the reaction of the Earth's atmospheric system to driving by the Sun, with the magnetosphere being labeled as a "compliant system" and the atmosphere labeled as a "persistent system" (Siscoe and Solomon 2006), the magnetosphere being very reactive (compliant) to the time-varying solar wind with the causes of magnetospheric storms clearly identifiable in the solar wind, whereas, on the contrary, there are no solar causes of hurricanes.

Driven A large number of statistical studies (e.g., Wygant et al. 1983; Newell et al. 2007, 2008; Borovsky and Denton 2014) have shown that the levels of the various measures of magnetospheric activity increase after certain parameters of the solar-wind change: this is perceived to be a driving of the system by the transport of mass and energy from the solar wind into the magnetosphere associated with the solar-wind control of the dayside reconnection rate. 


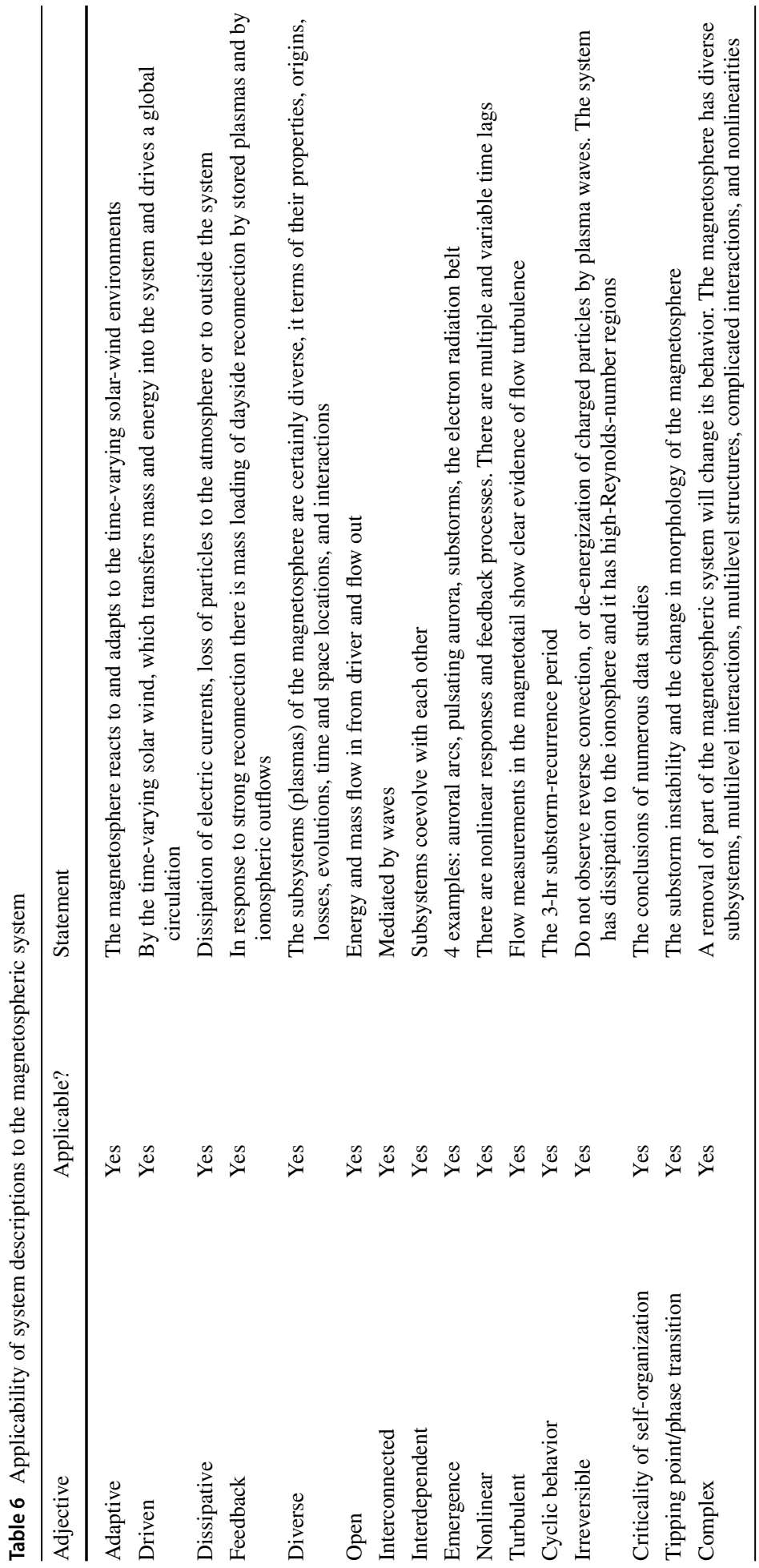


Dissipative The magnetospheric system has direct dissipation of electrical currents in the resistive ionosphere (Weimer 2005), which damps magnetospheric convection and may extract thermal energy from the magnetosphere in driving the currents with pressure gradients. Loss of magnetospheric ions and electrons into the atmosphere is also a form of dissipation (Emery et al. 2008), as is ion and electron loss across the magnetopause, reducing the total thermal energy of the system. Similarly, the charge exchange of hot ions with the cold neutral-hydrogen geocorona also represents thermal energy loss (Kozyra et al. 2002).

Feedback There are a couple of feedback loops in the magnetospheric system that can be identified. The first one (cf. Fig. 5) involves a feedback on solar-wind driving (Borovsky 2014a). (1) When the properties of the solar wind change to increase the dayside reconnection rate, (2) a stronger driving of the magnetosphere results, (3) this increases magnetospheric convection, and (4) the increased convection pulls some of the cold, dense, trapped plasmaspheric plasma out of the inner dipolar region to form a drainage plume. (5) The drainage plume convects to the dayside magnetosphere (6) where its high density acts to mass load the dayside reconnection rate, (7) reducing the rate at which the moving solar-wind plasma becomes magnetically connected to the Earth and reducing the driving of the magnetosphere by the solar wind. In a slightly different manner, the warm plasma cloak and the ion plasma sheet also partake in this feedback loop (Borovsky et al. 2013; cf. Fig. 5). A second feedback mechanism has been identified in computer simulations of the magnetosphere (Brambles et al. 2011; Ouellette et al. 2013). (1) At the start of a substorm, a new spot of reconnection occurs in the magnetotail near the Earth. (2) The enhanced substorm convection sends Poynting flux (Alfven waves) along the magnetic field from the reconnection site to the ionosphere. (3) The enhanced Poynting flux into the ionosphere causes a burst of $\mathrm{O}^{+}$outflow from the ionosphere into the magnetosphere. (4) When the $\mathrm{O}^{+}$reaches the reconnection site in the magnetotail, it mass loads the reconnection rate and shuts down the substorm.

Diverse See the discussion of the magnetosphere's diverse subsystems in Sect. 5, those various subsystems having diverse origins and diverse properties, and interacting with each other in diverse manners.

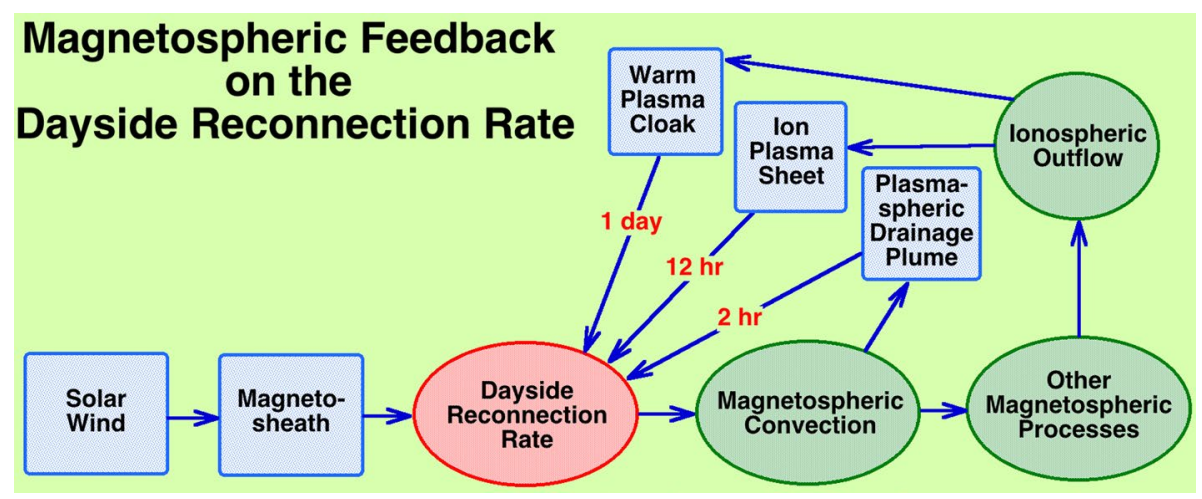

Fig. 5 An influence diagram focusing on the feedback of high-mass-density magnetospheric plasma (the plasmaspheric drainage plume, the warm plasma cloak, and ionospheric oxygen in the ion plasma sheet) on the dayside reconnection rate. Indicated in red are the approximate lag times for the three plasmas to arrive at the dayside reconnection site after a change in the solar wind produces an increase in the reconnection rate 
Open As discussed in Sect. 6, mass (and energy) enters into the system from the solar wind (magnetosheath) and from the ionosphere. Mass (and energy) exits the system across the magnetopause, into the atmosphere, and by charge exchange with the geocorona.

Interconnected The diverse types of plasma waves that couple the various subsystems of the magnetosphere are discussed in Sect. 6.

Interdependent The various plasmas of the magnetosphere coevolve owing to their interactions. A prime example of this is the coevolution is the plasmasphere and the electron radiation belt. Chorus waves exist outside of the plasmasphere and chorus waves act to energize (intensify) the electron radiation belt; hiss waves live inside the plasmasphere and hiss waves act to scatter the radiation-belt electrons into the atmosphere. When magnetospheric convection is strong, the plasmasphere has a small radius; at those times, chorus waves throughout the dipolar region act to intensify the electron radiation belt (Pierrard and Benck 2012). When magnetospheric convection weakens, the plasmasphere grows in radius and nearly fills the dipolar region; at those times, hiss waves throughout the dipolar region scatter the radiation-belt electrons into the atmosphere (Borovsky and Denton 2009), weakening the electron radiation belt. A repeated pattern can be seen: the plasmasphere shrinks in size and the electron radiation belt intensifies, and the plasmasphere grows in size and the electron radiation belt weakens (Goldstein et al. 2005). It is likely that another pattern of coevolution is intensifications of the electron plasma sheet and intensifications of the warm plasma cloak, with the electron plasma sheet somehow acting to intensify the ionospheric outflows that give rise to the warm plasma cloak.

Emergence See the four examples of emergence in Table 5 and the discussion of Sect. 8: auroral arcs, pulsating aurora, substorms, and the electron radiation belt.

Nonlinear There are several identified nonlinearities in the magnetospheric system as driven by the solar wind. One is a storage-release reaction to solar-wind driving (Baker et al. 1997) wherein under steady solar-wind driving (steady dayside reconnection rate) the magnetotail slowly accumulates magnetic flux and magnetic energy and then suddenly releases the energy when a substorm instability occurs in the tail. A second observed nonlinearity in the reaction of the magnetosphere to driving by the solar wind is the polar-cap potential saturation that occurs during some magnetospheric storms: here the current systems inside the magnetosphere reach a saturation intensity even though solar-wind driving can be stronger and stronger. Various mechanisms for the saturation have been suggested (Borovsky et al. 2009), but there is no consensus on which mechanisms are acting. A third nonlinearity is a hysteresis-like effect called the atmospheric flywheel effect (Richmond and Matsushita 1975) wherein ionospheric convection remains to be driven when solarwind driving shuts down owing to the inertia of the atmospheric convection pushing the ionosphere, where that atmospheric convection was itself driven by the previous solarwind-driven ionospheric convection. A fourth example: the reaction of the electron radiation belt to solar-wind driving and to driving by magnetospheric processes is known to be dependent on the time-integrals of the processes (Borovsky 2017b).

Turbulent For a dynamical system, the presence of flow turbulence implies several aspects of complexity including unpredictability, irreproducibility, irreversibility, crossscale coupling, enhanced dissipation, and mixing. Several examinations of the spacecraft-measured time series of the plasma-sheet velocity and magnetic field in the Earth's magnetotail have found the flows to be turbulent (Borovsky et al. 1997; Voros et al. 2004; Stepanova et al. 2009), with large-eddy spatial scales of $\sim 1 R_{\mathrm{E}}$ (e.g., the tangled magneticfield lines in Fig. 1). The plasma-sheet flows exhibit a classical turbulence power spectra of spatial scales (e.g., Kraichnan 1965; Boldyrev 2006), implying a cascade of energy from large scales to small scales. 
Cyclic behavior The Earth's magnetosphere exhibits cyclic behavior in its tendency for substorms (and global sawtooth oscillations) to recur with a $\sim 3$-h periodicity, that period being independent of substorm amplitude or phase of the solar cycle (Borovsky and Yakymenko 2017). What physically determines that the period should be $3 \mathrm{~h}$ in this storage-andrelease cycle is not known. One idea about the cause of the substorm-occurrence periodicity is a feedback cycle with ionospheric outflow [Brambles et al. 2011; Ouellette et al. 2013] (cf. feedback discussion above/below), but see Lund et al. (2018) for contrary evidence. Note that other periodicities in magnetospheric activity associated with periodicities of the solar-wind driving can be seen: a 24-hr period associated with change in the amount of dipole tilt associated with the Earth's rotation and a 27-day recurrence tendency for magnetospheric activity associated with the rotation period of the Sun (Denton et al. 2010).

Irreversible The magnetospheric system is irreversible for a number of reasons. First, the magnetosphere is dissipative (cf. the discussion above), with energy lost to the ionosphere, to the atmosphere, through the magnetopause, and via charge exchange. Second, the flows in the magnetotail plasma sheet are turbulent (see the discussion above); turbulent flows involve mixing and dissipation, making the flow irreversible. Third, the magnetospheric system is diffusive under the action of particle scattering by plasma waves (cf. Sect. 6). Fourth, under the action of magnetic reconnection plasma populations that become irreversibly mixed when they are magnetically connected (Gosling et al. 1990), which is irreversible. Finally, from an observer's point of view, nothing close to a reversal of the global convection pattern in the magnetosphere has ever been seen: when the conditions of the solar wind are favorable for reconnection to add magnetic flux to the dayside magnetosphere rather than remove it (e.g., Lavraud et al. 2006), a new convection pattern in the magnetosphere arises rather than a reversal of the standard pattern (Weimer et al. 2010).

Criticality of self-organizations As discussed in Sects. 8 and 10, several studies have found evidence of self-organized criticality in the behavior of the magnetospheric system (Klimas et al. 2000; Uritsky et al. 2002; Valdivia et al. 2005, 2006, 2013).

Tipping point/phase transition The occurrence of substorms (described either by a global plasma instability or as a manifestation of self-organized criticality) is an example of a tipping point where stored energy is released and the dynamics of the system suddenly changes (cf. Lewis 1991; Sitnov et al. 2000).

Complex It is sometimes stated that a system is complex if it behavior is unpredictable and/or surprising (e.g., McDaniel and Driebe 2005). To assess whether or not the magnetosphere is a complex system, we will use two definitions of complex. First (Bar-Yam 1997): a system is complex if the removal of a part of the system changes its behavior. We could envision the effect of removing the ionosphere from the magnetospheric system. Among other effects, this would remove ionospheric outflow of ions, which would (1) prevent the occurrence of the plasmasphere and the drainage plume, which in turn would (2) greatly alter the populations of plasma waves that energize and evolve the electron radiation belt and would (3) eliminate the feedback loop that reduces solar-wind/magnetosphere coupling when the coupling gets too strong (cf. Fig. 5). In the magnetosphere, every plasma population directly affects at least one other population, and that in fact affects the entire system. By this first definition of complex, the magnetosphere is a complex system. For the second definition of complex (Lin et al. 2013), we will quote four sentences and add italics: "The key that distinguishes complex systems from simple systems is the different significance of interactions and connections among the subsystems or components. Generally, the components that make up a complex system are not homogeneous and have multileveled structures. There are not only interactions between the components but also very 
complicated interactions among subsystems and between levels. Especially, some of these interactions are severely nonlinear." The magnetosphere is assessed against these statements, particularly the phrases marked in italics. (1) The components (subsystems here) of the magnetosphere are indeed diverse, not homogeneous (see Sect. 5, Table 2, and the discussion above). (2) There are multilevel interactions in the magnetosphere. An example is the ion plasma sheet simultaneously having microscopic and macroscopic interactions with the electron radiation belt (cf. Fig. 4). EMIC wave growth from free energy in the ion plasma sheet is a microscopic-level phenomena, as are wave-particle interactions when those waves pitch-angle scatter the electrons of the electron radiation belt (Thorne 2010); at the same time, the distortion of the magnetosphere's magnetic dipole by the pressure of the ion plasma sheet (ring current) is a macroscopic-level phenomena, as is the alteration of the spatial location of the electron radiation belt by those global magnetic-field distortions (Kim and Chan 1997). Another example of multilevel structures is the fact that magnetic-field-line reconnection is initiated and proceeds via physics in the electron diffusion region of the reconnection site (Hesse et al. 1999), which has a scale size of $\sim 1 \mathrm{~km}$, but that reconnection allows the global reconfiguration of the $250,000-\mathrm{km}$-diameter magnetotail to a lower energy state (Birn and Hones 1981). A final example of multilevel structures is the plasma waves of the magnetosphere. The plasmas of the magnetosphere have nonzero temperatures (cf. Fig. 2) so the generation and propagation of the waves in the magnetosphere depend on the microphysical (kinetic distribution functions) properties of the plasmas. For instance, in the magnetotail non-Maxwellian ion and electron distribution functions are observed (Runov et al. 2015). The non-Maxwellian distributions suggest that some energization mechanism is operating, and this mechanism changes the nature of the plasma waves, affecting the way the waves accelerate and energize other populations of particles (Navarro et al. 2014). (3) The interactions within the magnetosphere are very complicated. An example (see Fig. 4) is the interaction between the electron plasma sheet and the electron radiation belt. This interaction involves free energy being created in the electron plasma sheet by the occurrence of substorms, allowing the electron plasma sheet to drive whistler-mode waves: the plasmasphere controls at what locations in the magnetosphere there will be whistler-mode chorus (which energizes the electron radiation belt) or whistler-mode hiss (which scatters the electron radiation belt into the atmosphere). Additionally, the electron plasma sheet is the seed population for the substorm-injected electrons that are in turn the seed population for the electron radiation belt. (4) There are several nonlinearities in the response of the magnetospheric system to the time-varying solar winds. One global nonlinearity is the feedback loop wherein the magnetosphere acts to reduce solar-wind driving when the driving gets too strong (see Fig. 5 and the feedback discussion above). A second global nonlinearity is polar-cap potential saturation (see the nonlinear discussion above), where some of the reactions of the magnetosphere to the solar wind appear to saturate. A third nonlinearity is the atmospheric flywheel effect (see the nonlinear discussion above). There are also mesoscale feedback loops between auroral currents and ionospheric conductivity: the auroral currents and particle precipitation modify the ionospheric conductivity, with the ionospheric conductivity then modifying the auroral currents (Ebihara and Tanaka 2018). Finally, there is certainly global nonlinearity in the storage-and release of magnetic energy in the magnetotail (Baker et al. 1997), released by the occurrence of substorms. This storage-and-release in fact leads to a wellknown 3-hr periodicity to the reaction of the magnetosphere (periodic substorms or global sawtooth oscillations) to steady driving by the solar wind (Borovsky and Yakymenko 2017). A final example of nonlinearity is the interaction between storms and substorms (De Michelis et al. 2011), with storms being different because of substorms and substorm being 
different because of storms. Magnetospheric storms are associated with specific intervals of the solar wind that drive the magnetosphere to high levels of activity (Richardson et al. 2001; Siscoe and Solomon 2006). The intervals that drive the magnetosphere hard enough to produce a storm also drive substorms; hence, it would be unusual to have a storm without substorms. Storm phenomena would be different without substorms occurring. (A case in point is that substorms produce free energy for the driving of plasma waves that energize the electron radiation belt and substorms produce the seed electrons for the radiation belt (Su et al. 2014): without substorm occurrence, a storm probably would not produce a radiation-belt intensification.) Substorms are also different during storms owing to (a) the extreme distortion of the magnetosphere that occurs during a storm (Antonova 2002) and (b) the copious amounts of ionospheric plasma in the magnetosphere during a storm (Ono et al. 2010). By this second definition of complex, the magnetosphere is a complex system.

The magnetospheric system is certainly complicated, with long identifiable chain reactions wherein one thing gives rise to another which gives rise to yet another which gives rise etc., like Rube-Goldberg machines (Crease 2005). An example is sketched in Fig. 6,

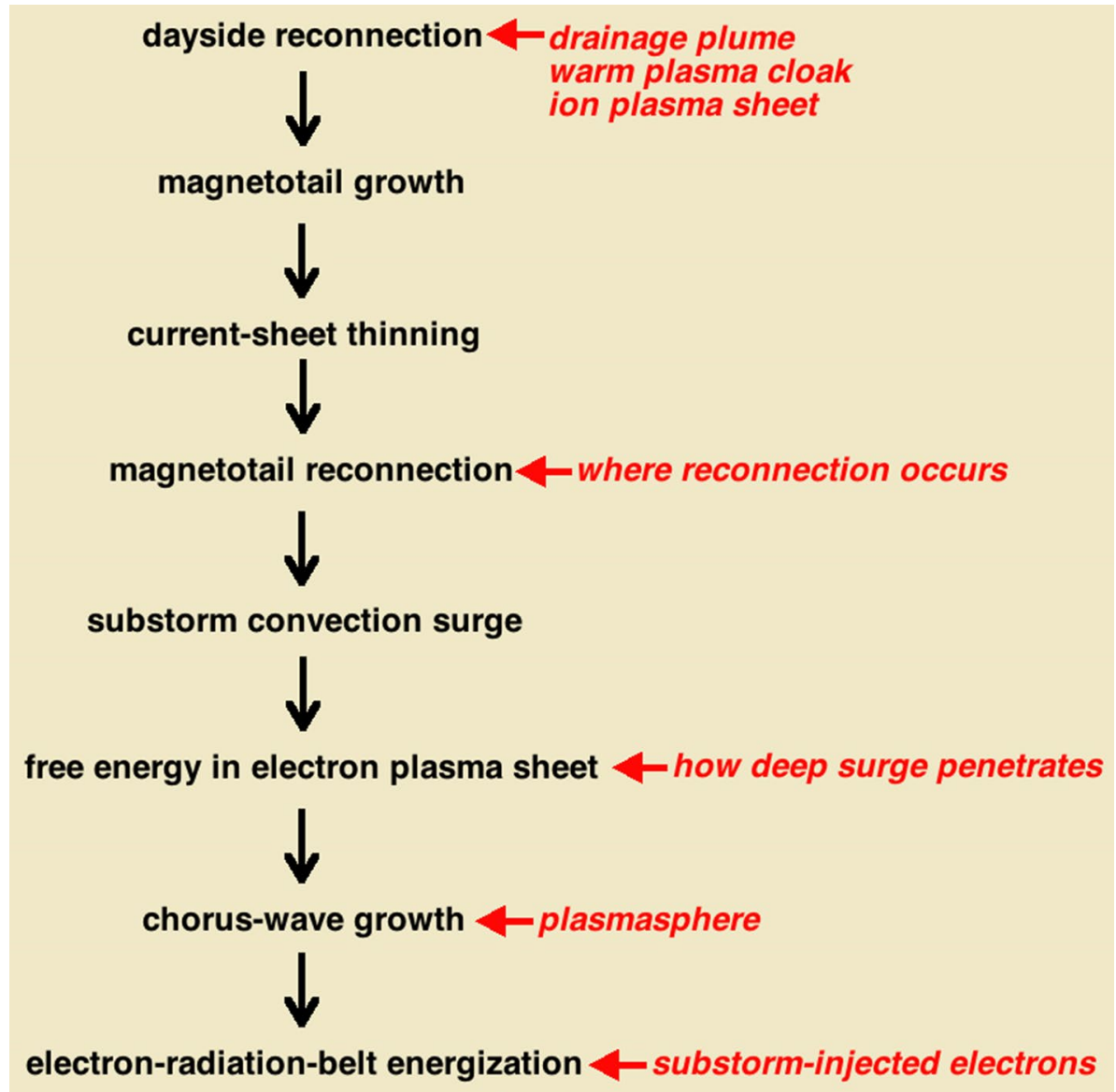

Fig. 6 A causal chain of events from dayside reconnection to electron-radiation-belt energization by chorus waves is outlined in black. Some extenuating factors that influence that chain are noted in red 
where dayside reconnection gives rise to the whistler-mode chorus waves that energize the electron radiation belt. [Compare the black portion of Fig. 6 with Fig. 1 of Crease (2005)]. Here the chain of reactions is outlined in black: dayside reconnection leads to magnetotail growth, which causes current-sheet thinning in the magnetotail, which leads to the onset of magnetotail reconnection, which produces a substorm convection surge earthward, which produces free energy in the electron-plasma-sheet population in the dipolar region, which causes whistler-mode chorus waves to grow, which energize radiation-belt electrons via wave-particle interactions. As an aside, note that the magnetosphere is a high-Reynoldsnumber fluid system, so that this chain of events is not entirely predictable or reproducible. But more importantly, this chain of events is also influenced by many other aspects of the magnetospheric system. Some of these are denoted in red in Fig. 6. From the top down, (a) the dayside reconnection rate is influenced by other plasmas in the magnetosphere, (b) where magnetotail reconnection occurs in the magnetotail depends on factors not yet understood, (c) how strong the convection surge is and how deep into the dipole it penetrates are controlled by factors not yet understood, and those strengths will determine whether free energy is given to the electron plasma sheet in the dipole. Continuing in Fig. 6, (d) where chorus waves grow depends on the state of the plasmasphere, and finally (e) how much energization the electron radiation belt obtains from the chorus waves depends on how many radiation-belt electrons were produced by substorm-injected electrons. Other linear chains could be drawn, such as dayside reconnection to the production of an auroral arc, or dayside reconnection to producing the warm plasma cloak (e.g., Fig. 5). But instead of being a simple set of linear chains of events, the operation of the magnetosphere is more like a tangle of Rube-Goldberg-like chains of events with the chains making multiple interactions and influencing each other. With these multiple connections, complicated moves to complex.

\section{Systems Science Work on the Magnetosphere}

The behavior of the magnetospheric system impacts the behavior of the broader Earth system (Tinsley 2000; Georgieva et al. 2005; Rycroft et al. 2012; Sinnhuber et al. 2012; Clilverd et al. 2016; Lam and Tinsley 2016). Research on "Earth systems science" can be divided into two categories (cf. Rousseau 2017): (1) employing system-level thinking (e.g., accounting for connectivity, utilizing a diversity of expertise) and (2) applying the science of systems to the Earth. Magnetospheric systems science can also be described by these two categories. System-level thinking is well developed within the field of magnetospheric research with a lot of the connectivity of the system being understood and more connectivity being discovered. Some connections within the magnetospheric system that were recently realized are listed in Table 7.

Systems science work on the Earth's magnetosphere driven by the time-dependent solar wind has been ongoing for decades, yet a treatment that accounts for all of the major subsystems and their interactions has not yet been attained.

In examining the behavior of the full, interconnected magnetospheric system, global physics-based simulation codes are probably the furthest along. The global-simulation codes solve the ideal-MHD equations in time on a three-dimensional grid, with a dipole magnetic field coming out of the Earth and the Earth's surface covered by an electrically resistive ionosphere and with a supersonic solar-wind plasma blowing at the Earth (Gombosi et al. 2000; White et al. 2001; Raeder et al. 2001; Lyon et al. 2004). Evolving 
Table 7 Recently uncovered connections in the magnetospheric system

\begin{tabular}{|c|c|}
\hline Connection & References \\
\hline $\begin{array}{l}\text { Mass loading of dayside reconnection rate by high-mass-density magneto- } \\
\text { spheric plasma }\end{array}$ & Borovsky and Steinberg (2006) \\
\hline $\begin{array}{l}\text { Magnetosonic waves driven by ion plasma sheet can energize radiation- } \\
\text { belt electrons }\end{array}$ & Horne et al. (2007) \\
\hline Role of geocorona in giving free energy to ion plasma sheet to drive waves & Meredith et al. (2008) \\
\hline Realization of the warm plasma cloak & Chappell et al. (2008) \\
\hline Radiation-belt electron scattering by plasmaspheric drainage plumes & Summers et al. (2008) \\
\hline Plasmaspheric hiss can come from whistler-mode chorus & $\begin{array}{l}\text { Bortnik et al. (2008) } \\
\text { Chum and Santolik (2005) }\end{array}$ \\
\hline Atmosphere chemistry affected by magnetospheric electrons & Verronen et al. (2011) \\
\hline Relation of auroral arcs to magnetotail stretching & Birn et al. (2012) \\
\hline Role of warm plasma cloak in modifying ULF wave properties & Takahashi et al. (2014) \\
\hline Radiation-belt electron acceleration by time-domain structures & Mozer et al. (2014) \\
\hline
\end{tabular}

versions of the global-MHD simulation codes involve adding a non-MHD model in the dipolar region of the magnetosphere to account for some aspects of magnetic drifts (Toffoletto et al. 2004; Welling and Ridley 2010; Yu et al. 2016; Jordanova et al. 2018), adding a model of the cold plasmasphere in the dipolar region (Ouellette et al. 2016), and adding ionospheric outflow (Glocer et al. 2009a; Brambles et al. 2011). These global-MHD simulations have been successful at reproducing several aspects of the system behavior of the magnetosphere as driven by the solar wind. But note that even the most-advanced physicsbased simulation codes still lack all of the magnetosphere's plasma populations, still lack the correct inter-plasma coupling mechanisms, and do not capture all types of magnetospheric activity. Additionally, the codes do not capture the wide range of time and spatial scales involved.

Simulating a more-reduced portion of the magnetospheric system, physics-based simulations codes for the electron-radiation-belt evolution have been developed that focus on the physical mechanisms that are most important to the electron belt (Bourdarie et al. 1996; Shprits et al. 2008a, b; Glocer et al. 2009b; Reeves et al. 2012; Fok et al. 2014). [There are much-less-sophisticated simulation codes for the ion radiation belt (e.g., Boscher et al. 1998; Vacaresse et al. 1999; Panasyuk 2004).] These physics-based codes have been successful at reproducing the major evolutionary aspects of the electron radiation belt as driven by magnetospheric convection and have been very useful for Gedanken experiments to explore the relative importance of various physical mechanisms.

There have also been simplified mathematical models built to look at the minimal descriptions needed to reproduce characteristic system reactions (such as substorm recurrence and chaos) to solar-wind driving (Smith et al. 1986; Goertz and Smith 1989; Goertz et al. 1991, 1993; Vassiliadis et al. 1993; Klimas et al. 1996, 1997, 2004; Horton and Doxas 1998; Valdivia et al. 1996, 1999, 2003, 2006; Freeman and Morley 2004; Spencer et al. 2006).

Most systems-science-oriented data analysis of the magnetosphere has focused on one aspect of magnetospheric activity at a time, usually on geomagnetic activity as measured by a single geomagnetic index. The goal of the data analysis has been to determine and analyze characteristic system behaviors of the magnetosphere, including 
examinations of chaotic output (Shan et al. 1991a, b; Sharma et al. 1993; Pavlos et al. 1994; Vassiliadis et al. 1995; Ukhorskiy et al. 2003), examination of multifracticality (Consolini et al. 1996; Voros and Jankovicova 2002; Consolini and De Michelis 2011), looking at the recurrence statistics of substorm events (Borovsky et al. 1993; Prichard et al. 1996; Morley et al. 2009; Forsyth et al. 2015; Chu et al. 2015; Borovsky and Yakymenko 2017), substorm amplitudes (Borovsky and Nemzek 1994; Morley et al. 2007; Borovsky and Yakymenko 2017), and examining data for evidence of self-organized criticality (Uritsky et al. 2001; Crosby et al. 2005; Sharma et al. 2005, 2016). In a similar vein, there has also been work to look at the amplitude scaling of auroralbrightening events in the upper atmosphere (Lui et al. 2000; Lui 2002, 2004; Uritsky et al. 2002).

In the spirit of analyzing the holistic behavior of the multiconnected magnetospheric system, data analysis of the multivariable solar wind (represented by a solar-wind state vector) driving the multivariable magnetosphere (represented by a magnetospheric state vector) has been performed, although not yet accounting for all of the major subsystems of the magnetosphere. Fung and coworkers (Fung and Shao 2008; Fung et al. 2016) have looked at independently predicting each element of a magnetospheric state vector from the full solar-wind state vector and then assembling a predicted magnetospheric state vector from its individually predicted elements. Magnetospheric state vectors with up to 4 dimensions (i.e., 4 simultaneous measures of the magnetosphere) have been assembled in this manner. To account for the interconnectedness of the magnetospheric system, Borovsky and Denton (Borovsky 2014b, 2018; Borovsky and Denton 2014,2018 ) looked at vector correlations between the time-dependent solar-wind state vector and the time-dependent magnetospheric state vector. This vector-vector correlation methodology reveals the simultaneous coupled reactions of multiple aspects of the magnetospheric system to driving by the solar wind. Magnetospheric state vectors involving up to 11 simultaneous magnetospheric measures (11 dimensions) have been utilized. Future studies using additional measures of the magnetosphere are planned.

Detailed descriptions of these and other systems science investigations of the Earth's magnetosphere can be found in the reviews by Voros (1994), Lakhina (1994), Vassiliadis (2000, 2006), Chapman et al. (2004), Valdivia et al. (2005, 2013), Sharma (2010, 2014), Pavlos et al. (2011) and Stepanova and Valdivia (2016).

A holistic systems science treatment of the coupled magnetospheric system is lacking, i.e., there has been no systems science research on the magnetosphere that deals with the diversity of its interconnected subsystems and the complexities of its varied interactions. And there has been insufficient coordination of magnetospheric science with the broader Earth systems science. Systems science has the potential to (1) inform about the behavior of the magnetosphere in response to the solar wind, (2) to find new phenomena, (3) to uncover rules, (4) to find hidden connections and unrealized feedback, and (5) to predict what is important to measure. As the present review points out, the magnetospheric system is unique, with its diverse subsystems, the huge ranges of important spatial and temporal scales, the driving by the time-varying solar wind, and the one-way coupling by plasma waves. Indeed, the global physics-based simulation codes that are designed for the magnetosphere are unique. A question can be asked: will unique systems science tools need to be developed to study the magnetospheric system? And can studying the magnetospheric system (and developing those tools) advance the "science of systems"? 


\section{Discussion: Critical Things That Are Not Known}

In Sect. 1, it is pointed out that a motivation for the present paper is the statement of Lin et al. (2013): "when hoping to understand the behaviors of a complex system, one needs to analyze not only how different components work together to form the behaviors of the whole system, but also the behaviors of the individual parts. Without deep and specific comprehension of the behaviors of the individual parts, there will be no way to capture the behaviors of the complex system." Further, in Sect. 10 the goal was stated of putting the entire magnetospheric system together to perform systems science on the entire integrated system. In hoping for that goal, one must unfortunately realize that not everything is known about the parts of the magnetospheric system, and probably not everything has been discovered.

At present, the field of magnetospheric physics is making great progress on understanding the underlying physical processes acting in the system (cf. Table 7), but the degree of maturity of the system understanding has not been assessed. From a systems science point of view, feedback phenomena are just being uncovered, coupling pathways and coupling mechanisms are still being explored, the multiple time lags in the system have yet to be surveyed, and large-scale systems simulations lack much of the relevant physics. Still, we believe that the progress in our understanding of how the different subsystems, and even levels within them, combined with the large amount of spatial and temporal data available in this magnetospheric system, provides a test bed to advance and test system sciences ideas, concepts, and techniques.

There are several identified outstanding unknowns about the Earth's magnetosphere (cf. Denton et al. 2016). A sampling is the following. (1) Our knowledge of how the solar wind couples to the Earth's magnetosphere is in general poor, with several fundamental basic-physics issues yet to be settled. (2) The mechanisms that manifest the inflow of plasma from the magnetosheath into the magnetosphere are poorly understood and what controls the amount of inflow is not known. (3) The physical mechanisms in the magnetosphere that extract energy and produce auroral arcs are not known. (4) The role of cold ions in the magnetosphere for controlling plasma waves is not fully understood, and the role of cold electrons in the magnetosphere for controlling plasma waves is very poorly understood. (5) Survey work is lacking that would tell us the general properties of the warm plasma cloak and that would give us a rudimentary understanding about its evolution. (6) To really understand the extent of wave-particle interactions among the plasmas of the magnetosphere, the time-varying properties of the plasma waves (intensities, frequency spectra, and distributions of wave-vector directions) need to be known everywhere (all radii, all latitudes, all longitudes), whereas there are no thorough surveys of these properties. Finally, (7) there is a lack of understanding of when, where, and by how much ionospheric ions flow out of the magnetosphere, a lack of understanding of the mechanisms producing the outflows, and a lack of understanding about what controls these outflows.

Acknowledgements The authors wish to thank Joachim Birn, Mick Denton, Mike Hartinger, Mike Liemohn, Bill Lotko, Michelle Thomsen, and Dan Welling for helpful conversations. Work at the Space Science Institute was supported by the NSF Geospace Environment Modeling Program via award AGS1502947, by the NASA Heliophysics Living with a Star program via Grants NNX16AB75G and NNX14AN90G, by the NSF Solar-Terrestrial Program via Grant AGS-12GG13659, by the NSF Solar Heliospheric and Interplanetary Environment program via ward AGS-1723416, and by the NASA Heliophysics Guest Investigator Program via Grants NNX17AB71G and NNX14AC15G. Work at the University of Chile was funded by Conicyt Pia Project ACT1405 and Fondecyt Project 1150718. 
Open Access This article is distributed under the terms of the Creative Commons Attribution 4.0 International License (http://creativecommons.org/licenses/by/4.0/), which permits unrestricted use, distribution, and reproduction in any medium, provided you give appropriate credit to the original author(s) and the source, provide a link to the Creative Commons license, and indicate if changes were made.

\section{References}

Andersson ME, Verronen PT, Wang S, Rodger CJ, Clilverd MA, Carson BR (2012) Precipitating radiation belt electrons and enhancements of mesospheric hydroxyl during 2004-2009. J Geophys Res 117(D09304):1-13

Antonova EE (2002) Storm-substorm relations and high latitude currents. Adv Space Res 30:2219-2224

Bailey J, Gruntman M (2013) Observations of exosphere variations during geomagnetic storms. Geophys Res Lett 40:1907-1911

Baker DN, Pulkkinen TI, Hesse M, McPherron RL (1997) A quantitative assessment of energy storage and release in the Earth's magnetotail. J Geophys Res 102:7159-7168

Balikhin MA, Boynton RJ, Walker SN, Borovsky JE, Billings SA, Wei HL (2011) Using the NARMAX approach to model the evolution of energetic electrons fluxes at geostationary orbit. Geophys Res Lett 38(L18105):1-5

Bar-Yam Y (1997) Dynamics of complex systems Ch. 0.1. Addison-Wesley, Reading

Beutier T, Boscher D, France M (1995) SALAMMBO: a three-dimensional simulation of the proton radiation belt. J Geophys Res 100:17181-17188

Birn J, Hones EW (1981) Three dimensional computer modeling of dynamic reconnection in the geomagnetic tail. J Geophys Res 86:6802-6808

Birn J, Priest ER (2009) Reconnection of Magnetic Field Lines. Cambridge University Press, Cambridge

Birn J, Thomsen MF, Borovsky JE, Reeves GD, McComas DJ, Bellian RD, Hesse M (1997) Substorm ion injections: geosynchronous observations and test particle orbits in three-dimensional dynamic MHD fields. J Geophys Res 102:2325-2341

Birn J, Thomsen MF, Borovsky JE, Reeves GD, McComas DJ, Belian RD, Hesse M (1998) Substorm electron injections: geosynchronous observations and test particle simulations. J Geophys Res 103:9235-9248

Birn J, Dorelli JC, Hesse M, Schindler K (2004) Thin current sheets and loss of equilibrium: three-dimensional theory and simulations. J Geophys Res 109(A02215):1-13

Birn J, Schindler K, Hesse M (2012) Magnetotail aurora connection: the role of thin current sheets. Geophys Monogr Ser 197:337-346

Blagoveshchenskii DV (2013) Effect of geomagnetic storms (substorms) on the ionosphere: 1. A review. Geomag Aeron 53:275-290

Blake JB, Baker DN, Turner N, Ogilvie KW, Lepping RP (1997) Correlation of changes in the outer-zone relativistic-electron population with upstream solar wind and magnetic field measurements. Geophys Res Lett 24:927-929

Boldyrev S (2006) Spectrum of magnetohydrodynamic turbulence. Phys Rev Lett 96:115002

Borovsky JE (1993) Auroral-arc thicknesses as predicted by various theories. J Geophys Res 98:6101-6138

Borovsky JE (2004) Global sawtooth oscillations of the magnetosphere. Eos Trans Am Geophys Union 85(49):525-526

Borovsky JE (2014a) Feedback of the magnetosphere. Science 343:1086-1087

Borovsky JE (2014b) Canonical correlation analysis of the combined solar-wind and geomagnetic-index data sets. J Geophys Res 119:5364-5381

Borovsky JE (2017a) Electrical conductivity channels in the atmosphere produced by relativistic-electron microbursts from the magnetosphere. J Atmos Solar-Terr Phys 155:22-26

Borovsky JE (2017b) Time-integral correlations of multiple variables with the relativistic-electron flux at geosynchronous orbit: the strong roles of the substorm-injected electrons and the ion plasma sheet. J Geophys Res 122:11961-11990

Borovsky JE (2018) A compact description of a time-dependent multivariable system and its time-dependent multivariable driver: reducing the system and driver state vectors to composite scalars. Adv Complex Systems (under review)

Borovsky JE, Denton MH (2006) The differences between CME-driven storms and CIR-driven storms. J Geophys Res 111(A07S08):1-17

Borovsky JE, Denton MH (2008) A statistical look at plasmaspheric drainage plumes. J Geophys Res 113(A09221):1-23 
Borovsky JE, Denton MH (2009) Electron loss rates from the outer electron radiation belt caused by the filling of the outer plasmasphere: the calm before the storm. J Geophys Res 114(A11203):1-12

Borovsky JE, Denton MH (2014) Exploring the cross-correlations and autocorrelations of the ULF indices and incorporating the ULF indices into the systems science of the solar-wind-driven magnetosphere. J Geophys Res 119:4307-4334

Borovsky JE, Denton MH (2018) Exploration of a composite index to describe magnetospheric activity: reduction of the magnetospheric state vector to a single scalar. J Geophys Res (under review)

Borovsky JE, Nemzek RJ (1994) Substorm statistics: occurrences and amplitudes. In: Proceedings of the second international conference on substorms, University of Alaska, pp 93-95

Borovsky JE, Steinberg JT (2006) The "calm before the storm" in CIR/magnetosphere interactions: occurrence statistics, solar-wind statistics, and magnetospheric preconditioning. J Geophys Res 111(A07S10):1-29

Borovsky JE, Yakymenko K (2017) Substorm occurrence rates, substorm recurrence times, and solarwind structure. J Geophys Res 122:2973-2998

Borovsky JE, Nemzek RJ, Belian RD (1993) The occurrence rate of magnetospheric-substorm onsets: random and periodic substorms. J Geophys Res 98:3807-3813

Borovsky JE, Elphic RC, Funsten HO, Thomsen MF (1997) The Earth's plasma sheet as a laboratory for turbulence in high-beta MHD. J Plasma Phys 57:1-34

Borovsky JE, Lavraud B, Kuznetsova MM (2009) Polar cap potential saturation, dayside reconnection, and changes to the magnetosphere. J Geophys Res 114(A03224):1-31

Borovsky JE, Denton MH, Denton RE, Jordanova VK, Krall J (2013) Estimating the effects of ionospheric plasma on solar-wind/magnetosphere coupling via mass loading of dayside reconnection: ion-plasma-sheet oxygen, plasmaspheric drainage plumes, and the plasma cloak. J Geophys Res 118:5695-5719

Borovsky JE, Cayton TE, Denton MH, Belian RD, Christensen RA, Ingraham JC (2016) The proton and electron radiation belts at geosynchronous orbit: statistics and behavior during high-speed-streamdriven storms. J Geophys Res 121:5449-5488

Bortnik J, Thorne RM, Meredith NP (2008) The unexpected origin of plasmaspheric hiss from discrete chorus emissions. Nature 452:62-66

Bortnik J, Chen L, Li W, Thorne RM, Horne RB (2011) Modeling the evolution of chorus waves into plasmaspheric hiss. J Geophys Res 116(A08221):1-13

Boscher D, Bourdarie S, Friedel R, Korth A (1998) Long term dynamic radiation belt model for low energy protons. Geophys Res Lett 25:4129-4132

Boudouridis A, Lyons LR, Zesta E, Weygand JM, Ribeiro AJ, Ruohoniemi JM (2011) Statistical study of the effect of solar wind dynamic pressure fronts on the dayside and nightside ionospheric convection. J Geophys Res 116(A10233):1-14

Bourdarie S, Boscher D, Beutier T, Sauvaud JA, Blanc M (1996) Magnetic storm modeling in the Earth's electron belt by the Salammbo code. J Geophys Res 101:17171-17176

Brambles OJ, Lotko W, Zhang B, Wiltberger M, Lyon J, Strangeway RJ (2011) Magnetosphere sawtooth oscillations induced by ionospheric outflow. Science 332:1183-1186

Burns AG, Killeen TL, Wang W, Roble RG (2004) The solar-cycle-dependent response of the thermosphere to geomagnetic storms. J Atmos Solar-Terr Phys 66:1-14

Chapman SC, Dendy RO, Watkins NW (2004) Robustness and scaling: key observables in the complex dynamic magnetosphere. Plasma Phys Control Fusion 46:B157-B166

Chappell CR, Huddleston MM, Moore TE, Giles BL, Delcourt DC (2008) Observations of the warm plasma cloak and an explanation of its formation in the magnetosphere. J Geophys Res 113(A09206):1-21

Chu X, McPherron RL, Hsu TS, Angelopoulos V (2015) Solar cycle dependence of substorm occurrence and duration: implications for onset. J Geophys Res 120:2808-2818

Chum J, Santolik O (2005) Propagation of whistler-mode chorus to low altitudes: divergent ray trajectories and ground accessibility. Ann Geophys 23:3727-3738

Clilverd MA, Rodger CJ, Andersson ME, Seppala A, Verronen PT (2016) Linkages between the radiation belts, polar atmosphere and climate: electron precipitation through wave particle interactions. In: Balasis G, Daglis IA, Mann IR (eds) Waves Particles and Storms in Geospace. Oxford University Press, Oxford, pp 354-376

Consolini G, De Michelis P (2011) Rank ordering multifractal analysis of the auroral electrojet index. Nonlin Processes Geophys 18:277-285

Consolini G, Marcucci MF, Candidi M (1996) Multifractal structure of auroral electrojet index data. Phys Rev Lett 76:4082-4085

Crease RP (2005) The appeal of Rube Goldberg. Phys World 18(6):19 
Crosby NB, Meredith NP, Coates AJ, Iles RHA (2005) Modelling the outer radiation belt as a complex system in a self-organised critical state. Nonlinear Process Geophys 12:993-1001

Cross MC, Hohenberg PC (1993) Pattern formation outside of equilibrium. Rev Mod Phys 65:851-1112

Darrouzet F, De Keyser J, Pierrard V (2009) The Earth's plasmasphere. Springer, New York

Dawes JHP (2010) The emergence of a coherent structure for coherent structures: localized states in nonlinear systems. Phil Trans Roy Soc A 368:3519-3534

De Michelis P, Consolini G, Materassi M, Tozzi R (2011) An information theory approach to the stormsubstorm relationship. J Geophys Res 116(A08225):1-9

Denton MH, Borovsky JE (2009) The superdense plasma sheet in the magnetosphere during high-speedsteam-driven storms: plasma transport timescales. J Atmos Solar-Terr Phys 71:1045-1058

Denton MH, Borovsky JE, Cayton TE (2010) A density-temperature description of the outer electron radiation belt during geomagnetic storms. J Geophys Res 115(A10208):1020

Denton MH, Borovsky JE, Stepanova M, Valdivia JA (2016) Unsolved problems of magnetospheric physics. J Geophys Res 121:10783-10785

Dungey JW (1961) Interplanetary magnetic field and the auroral zones. Phys Rev Lett 6:47-48

Eastwood JP, Hietala H, Toth G, Phan TD, Fujimoto M (2015) What controls the structure and dynamics of the Earth's magnetosphere? Space Sci Rev 188:251-286

Ebihara Y, Tanaka T (2018) Why does substorm-associated auroral surge travel westward? Plasma Phys Control Fusion 60(014024):1-8

Egeland AO, Holter O, Omholt A (1973) Cosmical geophysics. Universitetsforlaget, Oslo

Elphic RC, Thomsen MF, Borovsky JE, McComas DJ (1999) Inner edge of the electron plasma sheet: empirical models of boundary location. J Geophys Res 104:22679-22693

Emery BA, Coumans V, Evans DS, Germany GA, Greer MS, Holeman E, Kadinsky-Cade K, Rich FJ, Xu W (2008) Seasonal, Kp, solar wind, and solar flux variations in long-term single-pass satellite estimates of electron and ion auroral hemispheric power. J Geophys Rev 113(A06311):1-25

Fairfield DH (1971) Average and unusual locations of the Earth's magnetopause and bow shock. J Geophys Res 76:6700-6716

Falthammar CG (1973) Motion of charged particles in the magnetosphere. In: Egeland A, Holter O, Omholt A (eds) Cosmical geophysics. Universitetsforlaget, Oslo, pp 121-142

Feldstein YI, Galperin YI (1985) The auroral luminosity structure in the high-latitude upper atmosphere: its dynamics and relationship to the large-scale structure of the Earth's magnetosphere. Rev Geophys 23:217-275

Fok MC, Buzulukova NY, Chen SH, Glocer A, Nagai T, Valek P, Perez JD (2014) The comprehensive inner magnetosphere-ionosphere model. J Geophys Res 119:7522-7540

Forsyth C, Rae IJ, Coxon JC, Freeman MP, Jackman CM, Gjerloev J, Fazakerley AN (2015) A new technique for determining substorm onsets and phases from indices of the electrojet (SOPHIE). J Geophys Res 120:10592-10606

Freeman MP, Morley SK (2004) A minimal substorm model that explains the observed statistical distribution of times between substorms. Geophys Res Lett 31(L12807):1-4

Friedel RHW, Reeves GD, Obara T (2002) Relativistic electron dynamics in the inner magnetosphere-a review. J Atmos Solar-Terr Phys 64:265-282

Fuller-Rowell TJ, Codrescu MV, Moffett RJ, Quegan S (1994) Response of the thermosphere and ionosphere to geomagnetic storms. J Geophys Res 99:3893-3914

Fung SF, Shao X (2008) Specification of multiple geomagnetic responses to variable solar wind and IMF input. Ann Geophys 26:639-652

Fung SF, Tepper JA, Cai X (2016) Magnetospheric state of sawtooth events. J Geophys Res 121:7860-7869

Gary SP (1993) Theory of space plasma instabilities. Cambridge University Press, New York

Georgieva K, Kirov B, Atanassov D, Boneva A (2005) Impact of magnetic clouds on the middle atmosphere and geomagnetic disturbances. J Atmos Solar-Terr Phys 67:163-176

Glocer A, Toth Gombosi T, Welling D (2009a) Modeling ionospheric outflows and their impact on the magnetosphere, initial results. J Geophys Res 114(A05216):1-16

Glocer A, Toth G, Fok M, Gombosi T, Liemohn M (2009b) Integration of the radiation belt environment model into the space weather modeling framework. J Atmos Solar-Terr Phys 71:1653-1663

Goertz CK, Boswell RW (1979) Magnetosphere-ionosphere coupling. J Geophys Res 84:7239-7246

Goertz CK, Smith RA (1989) The thermal catastrophe model of substorms. J Geophys Res 94:6581-6596

Goertz CK, Smith RA, Shan LH (1991) Chaos in the plasma sheet. Geophys Res Lett 18:1639-1642

Goertz CK, Shan LH, Smith RH (1993) Prediction of geomagnetic activity. J Geophys Res 98:7673-7684

Goldstein J, Kanekal SG, Baker DN, Sandel BR (2005) Dynamic relationship between the outer radiation belt and the plasmapause during March-May 2001. Geophys Res Lett 32(L15104):1-4

Gombosi TI (1998) Physics of the space environment. Cambridge University Press, Cambridge 
Gombosi TI, De Zeeuw DL, Groth CPT, Powell KG (2000) Magnetospheric configuration for Parker-spiral IMF conditions: results of a 3D AMR MHD simulation. Adv Space Res 26:139-149

Gonzalez WD, Joselyn JA, Kamide Y, Kroehl HW, Rostoker G, Tsurutani BT, Vasyliunas VM (1994) What is a geomagnetic storm? J Geophys Res 99:5771-5792

Gosling JT, Thomsen MF, Bame SJ, Elphic RC, Russell CT (1990) Cold ion beams in the low latitude boundary layer during accelerated flow events. Geophys Res Lett 17:2245-2248

Grono EE, Donovan E, Murphy KR (2017) Tracking patchy pulsating aurora through all-sky images. Ann Geophys 35:777-784

Gvozdevsky BB, Sergeev VA (1996) MT-index - a possible new index to characterize the configuration of the magnetotail. Adv Space Res 18(8):51-54

Hargreaves JK (1992) The solar-terrestrial environment. Cambridge University Press, Cambridge

Hesse M, Birn J (2004) On the cessation of magnetic reconnection. Ann Geophys 22:603-612

Hesse M, Schindler K, Birn J, Kuznetsova M (1999) The diffusion region in collisionless magnetic reconnection. Phys Plasmas 6:1781-1795

Horne RB, Thorne RM, Glauert SA, Meredith NP, Pokhotelov D, Santolik O (2007) Electron acceleration in the Van Allen radiation belts by fast magnetosonic waves. Geophys Res Lett 42(L17107):1-5

Horton W, Doxas I (1998) A low-dimensional dynamical model for the solar wind driven geotail-ionosphere system. J Geophys Res 103:4561-4572

Huang CS, DeJong AD, Cai X (2009) Magnetic flux in the magnetotail and polar cap during sawteeth, isolated substorms, and steady magnetospheric convection intervals. J Geophys Res 114(A07202):1-13

Jaynes AM (2018) The origins of pulsating auroras. Nature 554:302-303

Jordanova VJ, Delzanno GL, Henderson MG, Godinez HC, Jeffrey CA, Lawrence EC, Morley SK, Moulton JD, Vernon LJ, Woodroffe JR, Brito TV, Engel MA, Meierbachtol CS, Svyatksy D, Yu Y, Toth G, Welling DT, Chen Y, Haiducek J, Markidis S, Albert JM, Birn J, Denton MH, Horne RB (2018) Specification of the near-Earth space environment with SHIELDS. J Atmos Solar Terr Phys. https:// doi.org/10.1016/j.jastp.2017.11.006 (in press)

Jursa AS (1985) Handbook of geophysics and the space environment. National Technical Information Service, Springfield

Kameda S, Ikezawa S, Sato M, Kuwabara M, Osada N, Murakami G, Yoshioka K, Yoshikawa I, Taguchi M, Funase R, Sugita S, Miyoshi Y, Fujimoto M (2017) Ecliptic north-south symmetry of hydrogen geocorona. Geophys Res Lett 44:11706-11712

Kasahara S, Miyohsi Y, Yokota S, Mitani T, Kasahara Y, Matsuda S, Kumamoto A, Matsuoka A, Kazama Y, Frey HU, Angelopoulos V, Kurita S, Keika K, Seki K, Shinohara I (2018) Pulsating aurora from electron scattering by chorus waves. Nature 554:337-340

Kaymaz Z (1998) IMP 8 magnetosheath field comparisons with models. Ann Geophys 16:376-387

Keiling A (2009) Alfven waves and their roles in the dynamics of the Earth's magnetotail: a review. Space Sci Rev 142:73-156

Kelley MC (1989) The Earth's ionosphere. Academic Press, San Diego, California

Kim HJ, Chan AA (1997) Fully adiabatic changes in storm time relativistic electrons fluxes. J Geophys Res 102:22107-22116

Kivelson MG, Russell CT (1995) Introduction to space physics. Cambridge University Press, New York

Klimas AJ, Vassiliadis D, Baker DN, Roberts DA (1996) The organized nonlinear dynamics of the magnetosphere. J Geophys Res 101:13089-13113

Klimas AJ, Vassiliadis D, Baker DN (1997) Data-derived analogues of the magnetospheric dynamics. JGR 102:26993-27009

Klimas AJ, Valdivia JA, Vassiliadis D, Baker DN, Hesse M, Takalo J (2000) Self-organized criticality in the substorm phenomenon and its relation to localized reconnection in the magnetospheric plasma sheet. J Geophys Res 105:18765-18780

Klimas AJ, Uritsky VM, Vassiliadis D, Baker DN (2004) Reconnection and scale-free avalanching in a driven current-sheet model. J Geophys Res 109(A02218):1-14

Komar CM, Cassak PA (2016) The local dayside reconnection rate for oblique interplanetary magnetic fields. J Geophys Res 121:5105-5120

Kozyra JU, Liemohn MW, Clauer CR, Ridley AJ, Thomsen MF, Borovsky JE, Roeder JL, Jordanova VK, Gonzalez WD (2002) Multistep Dst development and ring current composition changes during the 4-6 June 1991 magnetic storm. J Geophys Res 107(1224):1-33

Kraichnan RH (1965) Inertial-range spectrum of hydromagnetic turbulence. Phys Fluids 8:1385-1387

Kuwabara M, Yoshioka K, Murakami G, Tsuchiya F, kimura T, Yamazaki A, Yshikawa I (2017) The geocoronal responses to the geomagnetic disturbances. J Geophys Res 122:1269-1276

Lakhina GS (1994) Solar wind-magnetosphere-ionosphere coupling and chaotic dynamics. Surv Geophys. $15: 703-754$ 
Lam MM, Tinsley BA (2016) Solar wind-atmospheric electricity-cloud microphysics connections to weather and climate. J Atmos Solar-Terr Phys 149:277-290

Lavraud B, Thomsen MF, Lefebvre B, Schwartz SJ, Seki K, Phan TD, Wang YL, Fazakerley A, Rème H, Balogh A (2006) Evidence for newly closed magnetosheath field lines at the dayside magnetopause under northward IMF. J Geophys Res 111(A05211):1-10

Lei J, Thayer JP, Burns AG, Lu G, Deng Y (2010) Wind and temperature effects on thermosphere mass density response to the November 2004 geomagnetic storm. J Geophys Res 115(A05303):1-18

Lewis ZV (1991) On the apparent randomness of substorm onset. Geophys Res Lett 18:1627-1630

Liemohn MW, Kozyra JU, Thomsen MF, Roeder JL, Lu G, Borovsky JE, Cayton TE (2001) Dominant role of the asymmetric ring current in producing the stormtime Dst. J Geophys Res 106:10883-10904

Liemohn MW, Katus RM, Ilie R (2015) Statistical analysis of storm-time near-Earth current systems. Ann Geophys 33:965-982

Lin Y, Duan X, Zhao C, Xu L (2013) Systems science methodological approaches, Sect. 7.2.2. CRC Press, Boca Raton

Lu G, Richmond AD, Emery BA, Roble RG (1995) Magnetosphere-ionosphere-thermosphere coupling: effect of neutral winds on energy transfer and field-aligned current. J Geophys Res 100:19643-19659

Lui ATY (2002) Evaluation on the analogy between the dynamic magnetosphere and a forced and/or selforganized critical system. Nonlinear Process Geophys 9:399-407

Lui ATY (2004) Testing the hypothesis of the Earth's magnetosphere behaving like an avalanching system. Nonlinear Process Geophys 11:701-707

Lui ATY, Chapman SC, Liou K, Newell PT, Meng CI, Brittnacher M, Parks GK (2000) Is the dynamic magnetosphere an avalanching system? Geophys Res Lett 27:911-914

Lund EJ, Nowrouzi N, Kistler LM, Cai X, Frey HU (2018) On the role of ionospheric ions in sawtooth events. J Geophys Res 123:665-684

Lyon JG (2000) The solar wind-magnetosphere-ionosphere system. Science 288:1987-1991

Lyon JG, Fedder JA, Mobarry CM (2004) The Lyon-Fedder-Mobarry (LFM) global MHD magnetospheric simulation code. J Atmos Solar-Terr Phys 66:1333-1350

Lyons LR, Thorne RM, Kennel CF (1972) Pitch-angle diffusion of radiation belt electrons within the plasmasphere. J Geophys Res 77:3455-3474

Lysak RL (1990) Electrodynamic coupling of the magnetosphere and ionosphere. Space Sci Rev 52:33-87

McDaniel RR, Driebe DJ (eds) (2005) Uncertainty and surprise in complex systems. Springer, Berlin

McPherron RL, Russell CT, Aubry MP (1973) Satellite studies of magnetospheric substorms on August 15, 1968 9. Phenomenological model for substorms. J Geophys Res 78:3131-3149

Meredith NP, Cain M, Horne RB, Thorne RM, Summers D, Anderson RR (2003) Evidence for chorusdriven electron acceleration to relativistic energies from a survey of geomagnetically disturbed periods. J Geophys Res 108(1248):1-15

Meredith NP, Horne RB, Glauert SA, Thorne RM, Summers D, Albert JM, Anderson RR (2006) Energetic outer zone electron loss timescales during low geomagnetic activity. J Geophys Res 111(A05212):1-13

Meredith NP, Horne RB, Anderson RR (2008) Survey of magnetosonic waves and proton ring distributions in the Earth's inner magnetosphere. J Geophys Res 113(A06213):1-13

Min K, Liu K, Wang X, Chen L, Denton RE (2018) Fast magnetosonic waves observed by Van Allen Probes: testing local wave excitation mechanism. J Geophys Res 123:497-512

Mobus GE, Kalton MC (2015) Principles of systems science Sect. 10.3.4. Springer, New York

Morley SK, Freeman MP, Tanskanen EI (2007) A comparison of the probability distribution of observed substorm magnitude with that predicted by a minimal substorm model. Ann Geophys 25:2427-2437

Morley SK, Rouillard AP, Freeman MP (2009) Recurrent substorm activity during the passage of a corotating interaction region. J Atmos Solar-Terr Phys 71:1073-1081

Mozer FS, Agapitov O, Karsoselskikh V, Lejosne S, Reeves GD, Roth I (2014) Direct observation of radiation-belt electron acceleration from electron-Volt energies to megavolts by nonlinear whistler. Phys Rev Lett 113(035001):1-5

Navarro R, Moya PS, Munoz V, Araneda JA, Vinas AF, Valdivia JA (2014) Solar wind thermal induced magnetic fluctuations. Phys Rev Lett 112(245001):1-5

Nemecek Z, Safrankova J, Kruparova O, Prech L, Jelinek K, Dusik S, Simunek J, Grygorov K, Shue JH (2015) Analysis of temperature versus density plots and their relation to the LLBL formation under southward and northward IMF orientations. J Geophys Res 120:3475-3488

Newell PT, Sotirelis T, Liou K, Meng CI, Rich FJ (2007) A nearly universal solar wind-magnetosphere coupling function inferred from 10 magnetospheric state variables. J Geophys Res 112(A01206):1-16

Newell PT, Sotirelis T, Liou K, Rich FJ (2008) Pairs of solar wind-magnetosphere coupling functions: combining a merging term with a viscous term works best. J Geophys Res 113(A04218):1-10 
Newell PT, Liou K, Zhang Y, Sotirelis TS, Paxton LJ, Mitchell EJ (2016) Auroral precipitation models and space weather. Geophys Monogr Ser. 215:277-290

Nishida A (2000) The Earth's dynamic magnetotail. Space Sci Rev 91:507-577

Nishiyama T, Sakanoi T, Miyoshi Y, Kataoka R, Hampton D, Kathoh Y, Asamura K, Okano S (2012) Fine scale structure of pulsating auroras in the early recovery phase of substorm using ground-based EMCCD camera. J Geophys Res 117(A10229):1-17

Nykyri K, Otto A (2001) Plasma transport at the magnetospheric boundary due to reconnection in KelvinHelmholtz vortices. Geophys Res Lett 28:3565-3568

Oike Y, Kasahara Y, Goto Y (2014) Spatial distribution and temporal variations of occurrence frequency of lightning whistlers observed by VLF/WBA onboard Akebono. Radio Sci 49:753-764

Olson WP, Pfitzer KA (1974) A quantitative model of the magnetospheric magnetic field. J Geophys Res 79:3739-3748

Ono Y, Christon SP, Frey HU, Lui ATY (2010) Distribution of $\mathrm{O}^{+}$ions in the plasma sheet and locations of substorm onsets. J Geophys Res 115(A09220):1-8

Onsager TG, Green JC, Reeves GD, Singer HJ (2007) Solar wind and magnetospheric conditions leading to the abrupt loss of outer radiation belt electrons. J Geophys Res 112(A01202):1-9

Ostgaard N, Mende SB, Frey HU, Gladstone GR, Lauche H (2003) Neutral hydrogen density profiles derived from geocoronal imaging. J Geophys Res 108(1300):1-18

Otto A (2005) The magnetosphere. Lect Notes Phys 656:133-192

Ouellette JE, Brambles OJ, Lyon JG, Lotko W, Rogers BN (2013) Properties of outflow-driven sawtooth substorms. J Geophys Res 118:3223-3232

Ouellette JE, Lyon JG, Brambles OJ, Zhang B, Lotko W (2016) The effects of plasmaspheric plumes on dayside reconnection. J Geophys Res 121:4111-4118

Panasyuk M (2004) The ion radiation belts: Experiments and models. In: Daglis IA (ed) Effects of space weather on technology infrastructure. Kluwer Academic, The Netherlands, pp 65-90

Pavlos GP, Diamandidis D, Adamopuoulos A, Rigas AG, Daglis IA, Sarris ET (1994) Chaos and magnetospheric dynamics. Nonlinear Process Geophys 1:124-135

Pavlos GP, Iliopoulos AC, Athanasiou MA, Karakatsanis LP, Tsoutsouras VG, Sarris ET, Kyriakou GA, Rigas AG, Sarafopoulos DV, Anagnostopoulos GC, Diamandidis D, Dialetis D, Latousakis I, Liatsis PI, Andreadis I (2011) Complexity in space plasmas: universality of non-equilibrium physical processes. AIP Conf Proc 1320:77-81

Petrinec SM, Russell CT (1996) Near-Earth magnetotail shape and size as determined from the magnetopause flaring angle. J Geophys Res 101:137-152

Pierrard V, Benck S (2012) The dynamics of the terrestrial radiation belts and its links to the plasmasphere. AIP Conf Proc 1500:216-221

Prichard D, Borovsky JE, Lemons PM, Price CP (1996) Time dependence of substorm recurrence: an information-theoretic analysis. J Geophys Res 101:1535915369

Qin J, Waldrop L, Makela JJ (2017) Redistribution of H atoms in the upper atmosphere during geomagnetic storms. J Geophys Res 122:10686-10693

Raeder J, Wang YL, Fuller-Rowell TJ, Singer HJ (2001) Global simulation of magnetospheric space weather effects of the Bastille day storm. Solar Phys 204:325-338

Rees MH (1989) Physics and chemistry of the upper atmosphere, Sect. 8.3. Cambridge University Press, Cambridge

Reeves GD, Chen Y, Cunningham GS, Friedel RWH, Henderson MG, Jordanova VK, Koller J, Morley SK, Thomsen MF, Zaharia S (2012) Dynamic radiation environment assimilation model: DREAM. Space Weather 10(S03006):1-25

Reiff PH, Green JL, Benson RF, Carpenter DL, Calvert W, Fung SF, Gallagher DL, Reinisch BW, Smith MF, Taylor WWL (1994) Radio imaging of the magnetosphere. EOS Trans Amer Geophys Union 75(11):129-134

Richardson IG (2013) What in the solar wind does the Earth react to? AIP Conf Proc 1539:370-375

Richardson IG, Cliver EW, Cane HV (2001) Sources of geomagnetic storms for solar minimum and maximum conditions during 1972-2000. Geophys Res Lett 28:2569-2572

Richmond AD, Matsushita S (1975) Thermospheric response to a magnetic storm. J Geophys Res $80: 2839-2850$

Rodger CJ, Clilverd MA, McCormick RJ (2003) Significance of lightning-generated whistlers to inner radiation belt lifetimes. J Geophys Res 108:1462

Rodger CJ, Enell CF, Turunen E, Clilverd MA, Thomson NR, Verronen PT (2007) Lightning-driven inner radiation belt energy deposition into the atmosphere: implications for ionisation-levels and neutral chemistry. Ann Geophys 25:1745-1757 
Rodger CK, Clilverd MA, Seppala A, Thomson NR, Gamble RJ, Parrot M, Sauvaud JA, Ulich T (2010) Radiation belt electron precipitation due to geomagnetic storms: significance to middle atmosphere ozone chemistry. J Geophys Res 115(A11320):1-12

Rostoker G (1972) Geomagnetic indices. Rev Geophys Space Phys 10:935-950

Rousseau D (2017) Systems research and the quest for scientific systems principles. Systems 5(25):1-16 Royrvik O, Davis TN (1977) Pulsating aurora: local and global dynamics. J Geophys Res 82:4720-4740

Runov AV, Angelopoulos V, Gabrielse C, Liu J, Turner DL, Zhou XZ (2015) Average thermodynamic and spectral properties of plasma in and around dipolarizing flux bundles. J Geophys Res 120:4369-4383

Rycroft MJ, Israelsson S, Price C (2000) The global atmospheric electric circuit, solar activity and climate change. J Atmos Solar-Terr Phys 62:1563-1576

Rycroft MJ, Nicoll KA, Aplin KL, Harrison RG (2012) Recent advances in global electric circuit coupling between the space environment and the thermosphere. J Atmos Solar-Terr Phys 90-91:198-211

Safrankova J, Nemecek Z, Dusik S, Prech L, Sibeck DG, Borodkova NN (2002) Ann Geophys 30:301-309

Sandahl I (2003) The cusp as a source of plasma for the magnetosphere. Adv Space Res 31:1195-1205

Santolik O, Chum J (2009) The origin of plasmaspheric hiss. Science 324:729-730

Santolik O, Parrot M, Nemec F (2016) Propagation of equatorial noise to low altitudes: decoupling from the magnetosonic mode. Geophys Res Lett 43:6694-6704

Scourfield MWJ, Innes WF, Parsons NR (1972) Spatial coherency in pulsating aurora. Planet Space Sci 20:1843-1848

Seppala A, Clilverd MA, Beharrell MJ, Rodger CJ, Verronen PT, Andersson ME, Newnham DA (2015) Substorm-induced electron precipitation: impact on atmospheric chemistry. J Geophys Res 42:8172-8176

Shalizi CR, Haslinger R, Rouquier JB, Klinkner KL, Moore C (2006) Automatic filters for the detection of coherent structure in spatiotemporal systems. Phys Rev E 73(036104):1-16

Shan LH, Hansen P, Goertz CK, Smith RA (1991a) Chaotic appearance of the AE index. Geophys Res Lett 18:147-150

Shan LH, Goertz CK, Smith RA (1991b) On the embedding-dimension analysis of AE and AL time series. Geophys Res Lett 18:1647-1650

Sharma AS (2010) The magnetosphere: a complex driven system. AIP Conf Proc 1308:120-131

Sharma AS (2014) Complexity in nature and data-enabled science: the Earth's magnetosphere. AIP Conf Proc 1582:35-45

Sharma AS, Vassiliadis D, Papadopoulos K (1993) Reconstruction of low-dimensional magnetospheric dynamics by singular spectrum analysis. Geophys Res Lett 20:335-338

Sharma AS, Baker DN, Borovsky JE (2005) Nonequilibrium phenomena in the magnetosphere: Phase transition, self-organized criticality, and turbulence. In: Sharma AS, Kaw PK (eds) Nonequilibrium phenomena plasmas. Springer, New York, pp 3-22

Sharma AS, Aschwadnden MH, Crosby NB, Klimas AJ, Milovanov AV, Morales L, Sanchez R, Uritsky V (2016) 25 years of self-organized criticality: space and laboratory plasmas. Space Sci Rev 198:167-216

Shprits YY, Elkington SR, Meredith NP, Subbotin DA (2008a) Review of modeling of losses and sources of relativistic electrons in the outer radiation belt I: radial transport. J Atmos Solar-Terr Phys 70:1679-1693

Shprits YY, Subbotin DA, Meredith NP, Elkington SR (2008b) Review of modeling of losses and sources of relativistic electrons in the outer radiation belt II: local acceleration and losses. J Atmos Solar-Terr Phys 70:1694-1713

Sinnhuber M, Nieder H, Wieters N (2012) Energetic particle precipitation and the chemistry of the mesosphere/lower thermosphere. Surv Geophys 33:1281-1334

Siscoe GL (2011) Aspects of global coherence of magnetospheric behavior. J Atmos Solar-Terr Phys 73:402-419

Siscoe GL, Sanchez E (1987) An MHD model for the complete open magnetotail boundary. J Geophys Res 92:7405-7412

Siscoe G, Solomon SC (2006) Aspects of data assimilation peculiar to space weather forecasting. Space Weather 4(S04002):1-6

Sitnov MI, Sharma AS, Papadopoulos K, Vassiliadis D, Valdivia JA, Klimas AJ, Baker DN (2000) Phase transition-like behavior of the magnetosphere during substorms. J Geophys Res 105:12955-12974

Smith RA, Goertz CK, Grossman W (1986) Thermal catastrophe in the plasma sheet boundary layer. Geophys Res Lett 13:1380-1383

Spencer EW, Horton W, Doxas I (2006) The dynamics of storms and substorms with the WINDMI model. Adv Space Res 38:1657-1668 
Stassinopoulos EG, Verzariu P (1971) General formula for decay lifetimes of Starfish electrons. J Geophys Res 76:1841-1844

Stenzel RL (1999) Whistler waves in space and laboratory plasmas. J Geophys Res 104:14379-14395

Stepanova M, Valdivia JA (2016) Contribution of Latin-American scientists to the study of the magnetosphere of Earth. a review. Adv Space Res 58:1968-1985

Stepanova M, Antonova EE, Paredes-Davis D, Ovchinnikov IL, Yermolaev YI (2009) Spatial variation of eddy-diffusion coefficients in the turbulent plasma sheet during substorms. Ann Geophys 27:1407-1411

Stern DP (1996) A brief history of magnetospheric physics during the space age. Rev Geophys 34:1-31

Strangeway RJ (2012) The relationship between magnetospheric processes and auroral field-aligned current morphology. Geophys Monog Ser 197:355-364

Su Z, Zhu H, Xiao F, Zheng H, Wang Y, Zong QG, He Z, Shen C, Zhang M, Wang S, Kletzing CA, Kurth WS, Hospodarsky GB, Spence HE, Reeves GD, Funsten HO, Blake JB, Baker DN (2014) Quantifying the relative contributions of substorm injections and chorus waves to the rapid outward extension of electron radiation belt. J Geophys Res 119:10023-10040

Summers DB, Ni B, Meredith NP, Horne RB, Thorne RM, Moldwin MB, Anderson RR (2008) Electron scattering by whistler-mode ELF hiss in plasmaspheric plumes. J Geophys Res 113(A04219):1-17

Takahashi K, Anderson BJ (1992) Distribution of ULF energy (f $<80 \mathrm{mHz}$ ) in the inner magnetosphere: a statistical analysis of AMPTE CCE magnetic field data. J Geophys Res 97:10751-10773

Takahashi K, Denton RE, Hirahara M, Min K, Ohtani SI, Sanchez E (2014) Solar cycle variation of plasma mass density in the outer magnetosphere: magneoseismic analysis of toroidal standing Alfven waves detected by Geotail. J Geophys Res 119:8338-8356

Tanaka T (2007) Magnetosphere-ionosphere convection as a compound system. Space Sci Rev 133:1-72

Thomsen MF, McComas DJ, Borovsky JE, Elphic RC (1998) The magnetospheric trough. Geophys Monogr Ser 104:355-369

Thomsen MF, Denton MH, Gary SP, Liu K, Min K (2017) Ring/shell ion distributions at geosynchronous orbit. J Geophys Res 122:12055-12071

Thorne RM (2010) Radiation belt dynamics: the importance of wave-particle interactions. Geophys Res Lett 37(L22107):1-7

Tinsley BA (2000) Influence of solar wind on the global electric circuit, and inferred effects on cloud microphysics, temperature, and dynamics in the troposphere. Space Sci Rev 94:231-258

Toffoletto FR, Sazykin S, Spiro RW, Wolf RA, Lyon JG (2004) RCM meets LFM: initial results of oneway coupling. J Atmos Solar-Terr Phys 66:1361-1370

Tsurutani BT, Lakhina GS (1997) Some basic concepts of wave-particle interactions in collisionless plasmas. Rev Geophys 35:491-502

Turunen E, Verronen PT, Seppala A, Rodger CJ, Clilverd MA, Tamminen J, Enell CF, Ulich T (2009) Impact of different energies of precipitating particles on $\mathrm{NO}_{\mathrm{x}}$ generation in the middle and upper atmosphere during geomagnetic storms. J Atmos Solar-Terr Phys 71:1176-1189

Ukhorskiy AY, Sitnov MI, Sharma AS, Papadopoulos K (2003) Combining global and multi-scale features in a description of the solar wind-magnetosphere coupling. Ann Geophys 21:1913-1929

Uritsky VM, Pudovkin M, Steen A (2001) Geomagnetic substorms as perturbed self-organized critical dynamics of the magnetosphere. J Atmos Solar-Terr Phys 63:1415-1424

Uritsky VM, Klimas AJ, Vassiliadis D, Chua D, Parks G (2002) Scale-free statistics of spatiotemporal auroral emissions as depicted by POLAR UVI images: dynamic magnetosphere is an avalanching system. J Geophys Res 107(1426):1-7

Usanova ME, Mann IR, Bortnik J, Shao L, Angelopoulos V (2012) THEMIS observations of electromagnetic ion cyclotron wave occurrence: dependence on AE, SYMH, and solar wind dynamic pressure. J Geophys Res 117(A10218):1-13

Vacaresse A, Boscher D, Bourdarie S, Blanc M, Sauvaud JA (1999) Modeling the high-energy proton belt. J Geophys Res 104:28601-28613

Valdivia JA, Sharma AS, Papadopoulos K (1996) Prediction of magnetic storms by nonlinear models. Geophys Res Lett 23:2899-2902

Valdivia JA, Sharma AS, Papadopoulos K (1999) Spatiotemporal activity of magnetic storms. J Geophys Res 104:12239-12250

Valdivia JA, Klimas A, Vassiliadis D, Uritsky F, Takalo J (2003) Self-organization in a current sheet model. Space Sci Rev 107:515-522

Valdivia JA, Rogan J, Munoz V, Gomberoff L, Klimas A, Vassiliadis D, Uritsky V, Sharma S, Toledo B, Wastavino L (2005) The magnetosphere as a complex system. Adv Space Res 35:961-971

Valdivia JA, Rogan J, Munoz V, Toledo B (2006) Hysteresis provides self-organization in a plasma model. Space Sci Rev 122:313-320 
Valdivia JA, Rogan J, Munoz V, Toledo BA, Stepanova M (2013) The magnetosphere as a complex system. Adv Space Res 51:1934-1941

Valdivia JA, Toledo BA, Gallo N, Munoz V, Rogan J, Stepanova M, Moya PS, Navarro RE, Vinas AV, Araneda J, Lopez RA, Diaz M (2016) Magnetic fluctuations in anisotropic space plasmas: the effect of the plasma environment. Adv Space Res 58:2126-2133

Vassiliadis D (2000) System identification, modeling, and prediction for space weather environments. IEEE Trans Plasma Sci 28:1944-1955

Vassiliadis D (2006) Systems theory for geospace plasma dynamics. Rev Geophys 44(RG2002):1-39

Vassiliadis D, Sharma AS, Papadopoulos K (1993) An empirical model relating the auroral geomagnetic activity to the interplanetary magnetic field. Geophys Res Lett 20:1731-1734

Vassiliadis D, Klimas AJ, Baker DN, Roberts DA (1995) A description of the solar wind-magnetosphere coupling based on nonlinear filters. J Geophys Res 100:3495-3512

Verronen PT, Rodger CR, Clilverd MA, Wang S (2011) First evidence of mesospheric hydroxyl response to electron precipitation from the radiation belts. J Geophys Res 116:D07307

Verronen PT, Andersson ME, Rodger CF, Clilverd MA, Wang S, Turunen E (2013) Comparison of modeled and observed effects of radiation belt electron precipitation on mesospheric hydroxyl and ozone. J Geophys Res 118:11419-11428

Vogt J (2002) Alfven wave coupling in the auroral current circuit. Surv Geophys 23:335-377

Voros Z (1994) The magnetosphere as a nonlinear system. Stud Geophys Geod 38:168-186

Voros Z, Jankovicova D (2002) Neural network prediction of geomagnetic activity: a method using local Holder exponents. Nonlinear Process Geophys 9:425-433

Voros Z, Baumjohann W, Nakamura R, Volwerk M, Runov A, Zhang TL, Eichelberger HU, Treumann R, Georgescu E, Balogh Klecker B, Reme H (2004) Magnetic turbulence in the plasma sheet. J Geophys Res 109(A11215):1-16

Walker ADM (1993) Plasma waves in the magnetosphere. Springer, Berlin

Wang W, Burns AG, Wiltberger M, Solomon SC, Killeen TL (2008) Altitude variations of the horizontal thermospheric winds during geomagnetic storms. J Geophys Res 113(A02301):1-17

Weimer DR (2005) Improved ionospheric electrodynamic models and application to calculating Joule heating rates. J Geophys Res 110(A05306):1-21

Weimer DR, Ober DN, Maynard NC, Collier MR, McComas DR, Ness NF, Smith CW, Watermann J (2003) Predicting interplanetary magnetic field (IMF) propagation delay times using the minimum variance technique. J Geophys Res 108(1026):1-16

Weimer DR, Clauer CR, Engebretson MJ, Hansen TL, Gleisner H, Mann I, Yumoto K (2010) Statistical maps of geomagnetic perturbations as a function of the interplanetary magnetic field. J Geophys Res 115(A10320):1-21

Weimer DR, Bowman BR, Sutton EK, Tobiska WK (2013) Predicting global average thermospheric temperature changes resulting from auroral heating. J Geophys Res 116(A01312):1-15

Welling DT, Ridley AJ (2010) Validation of SWMF magnetic field and plasma. Sp Weather 8(S03002):1-11

Welling DT, Andre M, Dandouras I, Delcourt D, Fazakerley A, Fontaine D, Foster J, Ilie R, Kistler L, Lee JH, Liemohn MW, Slavin JA, Wang CP, Wiltberger M, Yau A (2015) The Earth: plasma sources, losses, and transport processes. Space Sci Rev 192:145-208

White WW, Schoendorf JA, Siebert KD, Maynard NC, Weimer DR, Wilson GL, Sonnerup BUO, Siscoe GL, Erickson GM (2001) MHD simulation of magnetospheric transport at the mesoscale. In: Song P, Singer H, Siscoe G (eds) Space Weather. American Geophysical Union, Washington, pp 229-240

Wright AN (1996) Transfer of magnetosheath momentum and energy to the ionosphere along open field lines. J Geophys Res 101:13169-13178

Wygant JR, Torbert RB, Mozer FS (1983) Comparison of S3-3 polar cap potential drops with the interplanetary magnetic field and models of magnetopause reconnection. J Geophys Res 88:5727-5735

Yamamoto T (1988) On the temporal fluctuations of pulsating auroral luminosity. J Geophys Res 93:897-911

Yu Y, Jordanova VK, Ridley AJ, Albert JM, Horne RB, Jeffery CA (2016) A new ionospheric electron precipitation module coupled with RAM-SCB within the geospace general circulation model. J Geophys Res 121:8554-8575 